Article

\title{
Vertical Structure of Ice Clouds and Vertical Air Motion from Vertically Pointing Cloud Radar Measurements
}

\author{
Bo-Young Ye ${ }^{1(\mathbb{D}}$ and GyuWon Lee ${ }^{2, *}$ \\ 1 Institute of Environmental Studies, Pusan National University, Busan 46241, Korea; boyoungye@pusan.ac.kr \\ 2 Department of Astronomy and Atmospheric Sciences, Center for Atmospheric Remote Sensing (CARE), \\ Kyungpook National University, Daegu 41566, Korea \\ * Correspondence: gyuwon@knu.ac.kr; Tel.: +82-53-950-6361
}

Citation: Ye, B.-Y.; Lee, G. Vertical Structure of Ice Clouds and Vertical Air Motion from Vertically Pointing Cloud Radar Measurements. Remote Sens. 2021, 13, 4349. https://doi.org/ $10.3390 / \mathrm{rs} 13214349$

Academic Editor: Filomena Romano

Received: 28 September 2021

Accepted: 26 October 2021

Published: 29 October 2021

Publisher's Note: MDPI stays neutral with regard to jurisdictional claims in published maps and institutional affiliations.

Copyright: (c) 2021 by the authors. Licensee MDPI, Basel, Switzerland. This article is an open access article distributed under the terms and conditions of the Creative Commons Attribution (CC BY) license (https:// creativecommons.org/licenses/by/ $4.0 /)$.
Abstract: The vertical structure of ice clouds and vertical air motion $\left(V_{\text {air }}\right)$ were investigated using vertically pointing Ka-band cloud radar. The distributions of reflectivity $(Z)$, Doppler velocity $\left(V_{D}\right)$, and spectrum width (SW) were analyzed for three ice cloud types, namely, cirrus, anvil, and stratiform clouds. The radar parameters of the cirrus clouds showed narrower distributions than those of the stratiform and anvil clouds. In the vertical structures, the rapid growth of $Z$ and $V_{D}$ occurred in the layer between 8 and $12 \mathrm{~km}$ (roughly a layer of $-40^{\circ} \mathrm{C}$ to $-20^{\circ} \mathrm{C}$ ) for all ice clouds.

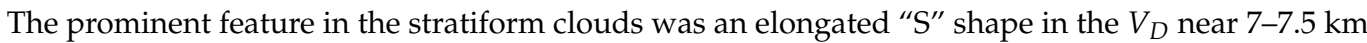
(at approximately $-16{ }^{\circ} \mathrm{C}$ to $-13{ }^{\circ} \mathrm{C}$ ) due to a significant decrease in an absolute value of $V_{D}$. The mean terminal fall velocity $\left(V_{t}\right)$ and $V_{\text {air }}$ in the ice clouds were estimated using pre-determined $V_{t}-Z$ relationships $\left(V_{t}=a Z^{b}\right)$ and the observed $V_{D}$. Although the cirrus clouds demonstrated wide distributions in coefficients $a$ and exponents $b$ depending on cloud heights, they showed a smaller change in $Z$ and $V_{t}$ values compared to that of the other cloud types. The anvil clouds had a larger exponent than that of the stratiform clouds, indicating that the ice particle density of anvil clouds increases at a faster rate compared with the density of stratiform clouds for the same $Z$ increment. The significant positive $V_{\text {air }}$ appeared at the top of all ice clouds in range up to $0.5 \mathrm{~m} \mathrm{~s}^{-1}$, and the anvil clouds showed the deepest layer of upward motion. The stratiform and anvil clouds showed a dramatic increase in vertical air motion in the layer of $6-8 \mathrm{~km}$ as shown by the rapid decrease of $V_{D}$. This likely caused increase of supersaturation above. A periodic positive $V_{\text {air }}$ linked with a significant reduction in $V_{D}$ appeared at the height of 7-8 $\mathrm{km}$ (approximately $-15^{\circ} \mathrm{C}$ ) dominantly in the stratiform clouds. This layer exhibited a bi-modal power spectrum produced by pre-existing larger ice particles and newly formed numerous smaller ice particles. This result raised a question on the origins of smaller ice particles such as new nucleation due to increased supersaturation by upward motion below or the seeder-feeder effect. In addition, the retrieved $V_{\text {air }}$ with high-resolution data well represented a Kelvin-Helmholtz wave development.

Keywords: ice clouds; vertical structure; vertical air motion; terminal velocity; cloud radar; $V_{t}-Z$ relationship, bi-modal power spectrum

\section{Introduction}

Ice clouds are a major factor of global radiation equilibrium, which has a strong influence on climate change and the greenhouse effect on Earth, and they have played an important role in numerical forecasts and climate models [1,2]. The parameterization of ice clouds in numerical models plays an essential role in the accuracy of forecasts [3]. The terminal fall velocity $\left(V_{t}\right)$ of a hydrometeor is the most important parameter in ice cloud parameterization, and it strongly influences the sedimentation of ice crystals in numerical models [4-7]. Hong et al. [8] showed that microphysical processes with ice sedimentation reveal significant improvement in the amount of high cloud and precipitation of weather forecasting models. 
Ice clouds are globally distributed with large spatial and temporal variability. The microphysical (e.g., particle size, number concentration, particle density, and particle habit) and macrophysical (e.g., bottom and top height, amount, and thickness) characteristics of ice clouds have been studied to understand their complexities [9-18]. In particular, the microphysics of ice clouds are controlled by vertical air motion $\left(V_{\text {air }}\right)$ [19]. Protat and Williams [20] underlined that the $V_{t}$ of ice particles and their variability from long-term observations are needed to understand the dynamics linked to large-scale environments. According to Heymsfield and Westbrook [21], $V_{t}$ varies with the type of ice particles in in situ measurements and laboratory experiments.

To provide a better understanding of the dynamical properties of ice clouds, observations made with remote sensing equipment, particularly ground-based cloud radar, are useful $[22,23]$. The cloud radar provides high-quality information about the presence of clouds. Moreover, the particle size and number concentration of ice crystals in ice clouds vary in time and space due to the microphysical properties, which are reflected in the observed reflectivity $(Z)$ and Doppler velocity $\left(V_{D}\right)$ from the vertically pointing cloud radars. $Z$ differs by the type and depth of the ice cloud.

$V_{D}$ is determined by the falling speed of ice crystal particles and ambient vertical air velocity, $V_{\text {air }}$. Ice cloud studies have been performed to identify their characteristics in terms of their types and regions using the decomposition technique of $V_{D}[10,20,24-28]$. These studies have used the assumption that the mean $V_{\text {air }}$ can vanish with respect to the mean $V_{t}$ over a given period due to its smaller scale features. Protat and Williams [20] proposed the retrieval technique of $V_{t}$ using the $V_{t}-Z$ relationship and found that it has residuals of less than $0.1 \mathrm{~m} \mathrm{~s}^{-1}$. The retrieved $V_{t}$ can be used in microphysical studies because the error is sufficiently small [29]. Kalesse et al. [26] estimated $V_{t}$ using the $V_{t}-Z$ relationship and demonstrated that the microphysical processes of ice clouds are linked with cloud thickness.

Observational studies of ice clouds in Korea have been performed using various equipment $[18,30]$. Kim et al. [30] compared the determined geometrical properties (e.g., heights of cloud base and top) and optical properties (e.g., cloud optical depth) to determine cloud vertical structures by using ground-based lidar and space-borne Cloud-Aerosol Lidar with Orthogonal Polarization (CALIOP) over the region of Seoul. They showed that a distinct monthly variation in cirrus altitudes is related to a monthly variation in tropopause height. Ye et al. [18] found that the ice clouds classified as high clouds have a significant seasonal variation in their maximum height.

The objective of this study is to analyze ice cloud dynamics with retrieved $V_{t}$ and $V_{a i r}$ from vertical pointing measurements of the Ka-band cloud radar collected in Boseong, Korea. The study examines ice cloud properties and estimates $V_{t}$ and $V_{\text {air }}$ for classified types. A brief description of cloud measurements and the estimation of $V_{t}$ and $V_{\text {air }}$ for ice clouds are explained in Sections 2 and 3. The results and conclusions are presented in Sections 4 and 5.

\section{Data}

A Ka-band cloud radar is installed in the Boseong standard weather observatory $\left(34.76^{\circ} \mathrm{N}, 127.21^{\circ} \mathrm{E}\right)$ surrounded by agricultural land facing the southern coast of the Korean Peninsula (See Figure 1 of Ye et al. [18]). The cloud radar transmits a horizontally polarized electromagnetic wave with a magnetron transmitter (maximum power of $15 \mathrm{~kW}$ ) in a frequency of $33.44 \mathrm{GHz}$ (wavelength $8.9 \mathrm{~mm}$ ) and receives backscattered signals by targets in horizontal and vertical polarization. Thus, the radar produces only a dualpolarization variable (linear depolarization ratio, LDR) and other single-polarization variables $\left(Z, V_{D}\right.$, and spectrum width $\left.(\mathrm{SW})\right)$. The antenna diameter is $1.5 \mathrm{~m}$ with a beamwidth of $0.5^{\circ}$. Detailed specifications are shown in Table 1. 

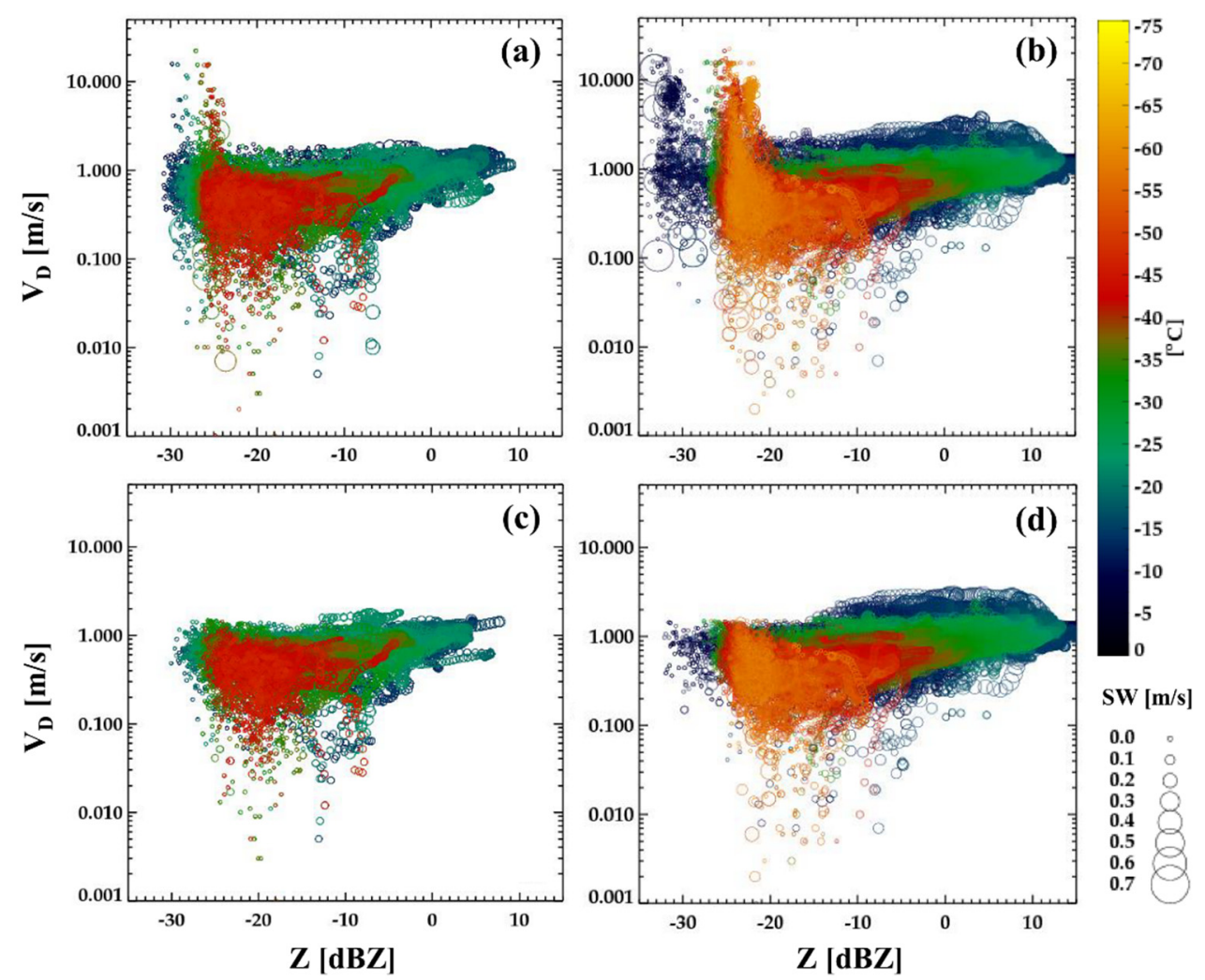

Figure 1. Scatterplots of Doppler velocity $\left(V_{D}\right)$ as a function of reflectivity $(Z)$ of (a) before and (c) after applying quality control to a case of cirrus clouds on 25 September 2014 and (b) before and (d) after applying quality control for a case of anvil clouds on 22 May 2015. Circles indicate SW. Color represents atmosphere temperature from sounding measurements.

Table 1. Specifications of the Ka-band cloud radar.

\begin{tabular}{cc}
\hline Parameter & Value \\
\hline Frequency (wavelength) & $33.44 \mathrm{GHz}(8.9 \mathrm{~mm})$ \\
\hline Transmitter & Magnetron \\
\hline Peak power & $\geq 15 \mathrm{~kW}$ \\
\hline Antenna diameter & $1.5 \mathrm{~m}$ \\
\hline Beamwidth & $0.42^{\circ}$ \\
\hline Gate spacing/maximum range & $15 \mathrm{~m} / 15 \mathrm{~km}$ \\
\hline Polarization mode & Single transmitting, dual receiving \\
\hline Product & $\begin{array}{c}\text { Linear depolarization ratio (LDR), } \\
\text { radar reflectivity (Z), Doppler velocity }\left(V_{D}\right), \\
\text { spectrum width (SW) }\end{array}$ \\
\hline
\end{tabular}

Although the contamination by the non-meteorological echoes near the ground can be avoided, the removal processes of noise echo and outlier are essential for the analysis of ice clouds. If the hardware burst power was less than $75 \mathrm{~dB}$, the data were treated as noise and were removed. To derive an accurate $V_{t}-Z$ relationship, the quality control of radar parameters was conducted in three steps. The noise had high values of LDR and $Z$ in the vertical direction. If the average LDR of each ray was larger than $5 \mathrm{~dB}$ or the average $Z$ of each ray was larger than $30 \mathrm{dBZ}$, the ray data were eliminated for the first step. The outliers were then removed using the following thresholds: $\pm 3 \sigma$ for $Z$ and $V_{D}$, $\mathrm{SW}>0.5 \mathrm{~m} \mathrm{~s}^{-1}$, and $V_{D}>1.5 \mathrm{~m} \mathrm{~s}^{-1}$ for weak echoes $(Z<-15 \mathrm{dBZ})$. A cloud was defined 
as having a thickness of greater than $500 \mathrm{~m}$. In the final step, the cloud edge ( 3 pixels) and the clouds with a thickness of $<500 \mathrm{~m}$ were excluded.

Before applying the quality control, a $V_{D}$ larger than $1.5 \mathrm{~m} \mathrm{~s}^{-1}$ or an SW of larger than $0.5 \mathrm{~m} \mathrm{~s}^{-1}$ in weak cloud echoes $(Z<-15 \mathrm{dBZ})$ frequently appeared in the case of anvil clouds (Figure 1), but after the quality control process was implemented, these echoes were removed. Echoes at the high altitude with low temperatures had a lower $Z$ and a lower $V_{D}$ than the cloud echoes at lower altitudes with higher temperatures.

Time-height cross-sections of radar parameters before and after quality control for a case of cirrus clouds on 9 August 2015 are shown in Figure 2. The cloud echoes had a thickness of approximately 3 to $5 \mathrm{~km}$ and developed a height of up to $12 \mathrm{~km}$ from 12 to 17 UTC. As the $Z$ increased, the $V_{D}$ increased with the decrease in height. The fall streaks clearly showed the growth of cloud particles. The SW of the cirrus cloud was less than $0.15 \mathrm{~m} \mathrm{~s}^{-1}$, except for at the bottom of cloud echoes with a height of lower than $8 \mathrm{~km}$. After applying quality control, the cloud echoes with a weak $Z$ under $-20 \mathrm{dBZ}$ were slightly removed from 05 to 08 UTC.
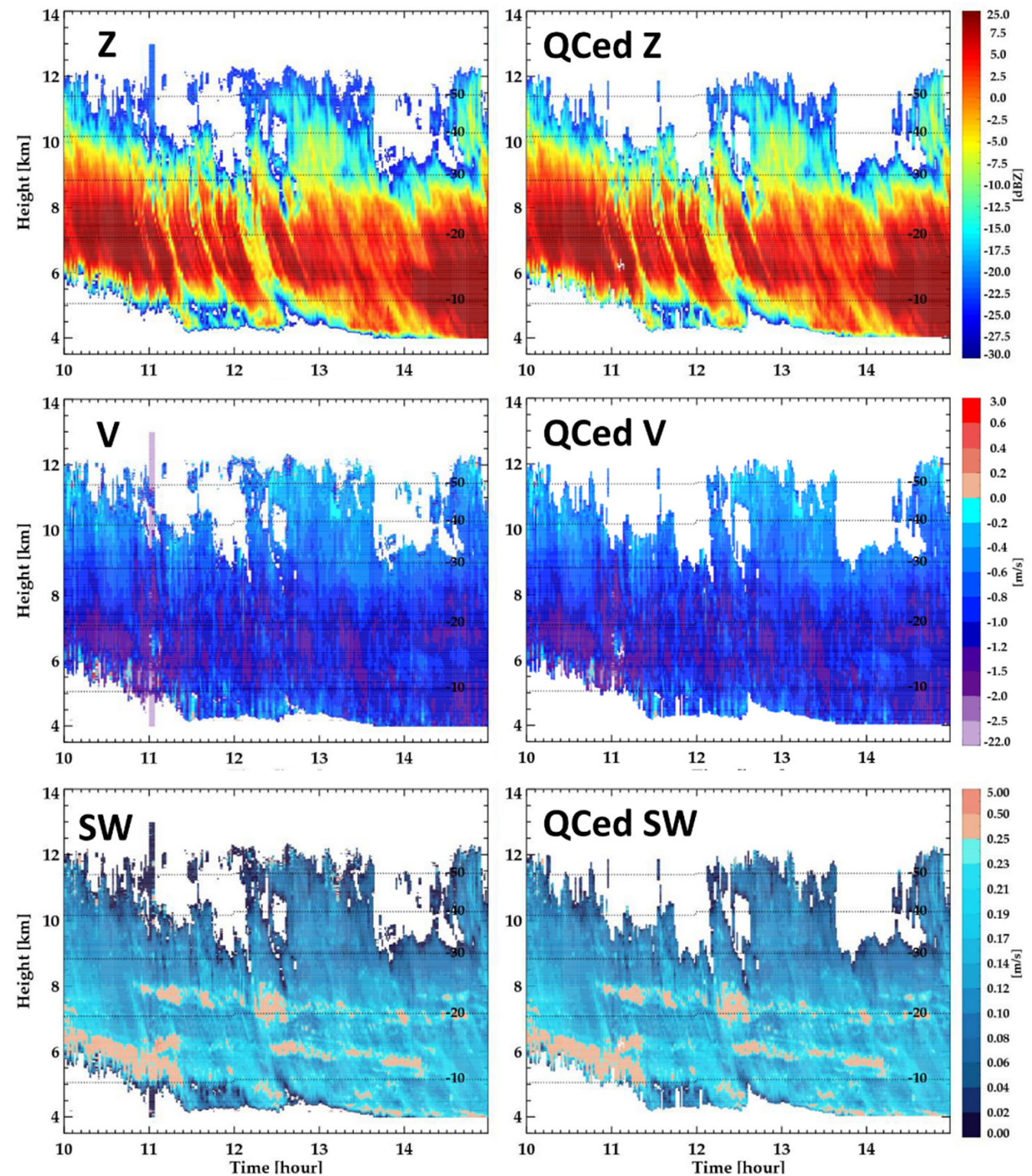

Figure 2. Time-height cross-sections of $Z, V_{D}$, and $S W$ of (left) before and (right) after applying quality control for a case of anvil on 22 May 2015. Dotted line is temperature from sounding data. 


\section{Methods}

\subsection{Classification of Ice Clouds}

Ice clouds were classified into three types (cirrus clouds: cirrus; stratiform precipitation: stratiform; thick non-precipitating anvils: anvil) using a $1 \mathrm{~min} Z$ profile, similar to the classification criteria used by Protat and Williams [20]. The cirrus (cirrus clouds) type had a base height above $6 \mathrm{~km}$ (marked by $\mathrm{C}$ in Figure 3). The stratiform type was classified as the upper part of the stratiform (stratiform precipitation) showing a melting layer $\left(0^{\circ} \mathrm{C}\right.$ height; $\mathrm{S}$ part in Figure 3). The anvil (thick non-precipitating anvils) type was defined as a thick cloud that had a bottom height above $3 \mathrm{~km}$ and a top height above $6 \mathrm{~km}$ with the precipitation not reaching the ground, as shown in the area indicated by $\mathrm{A}$ in Figure 3.
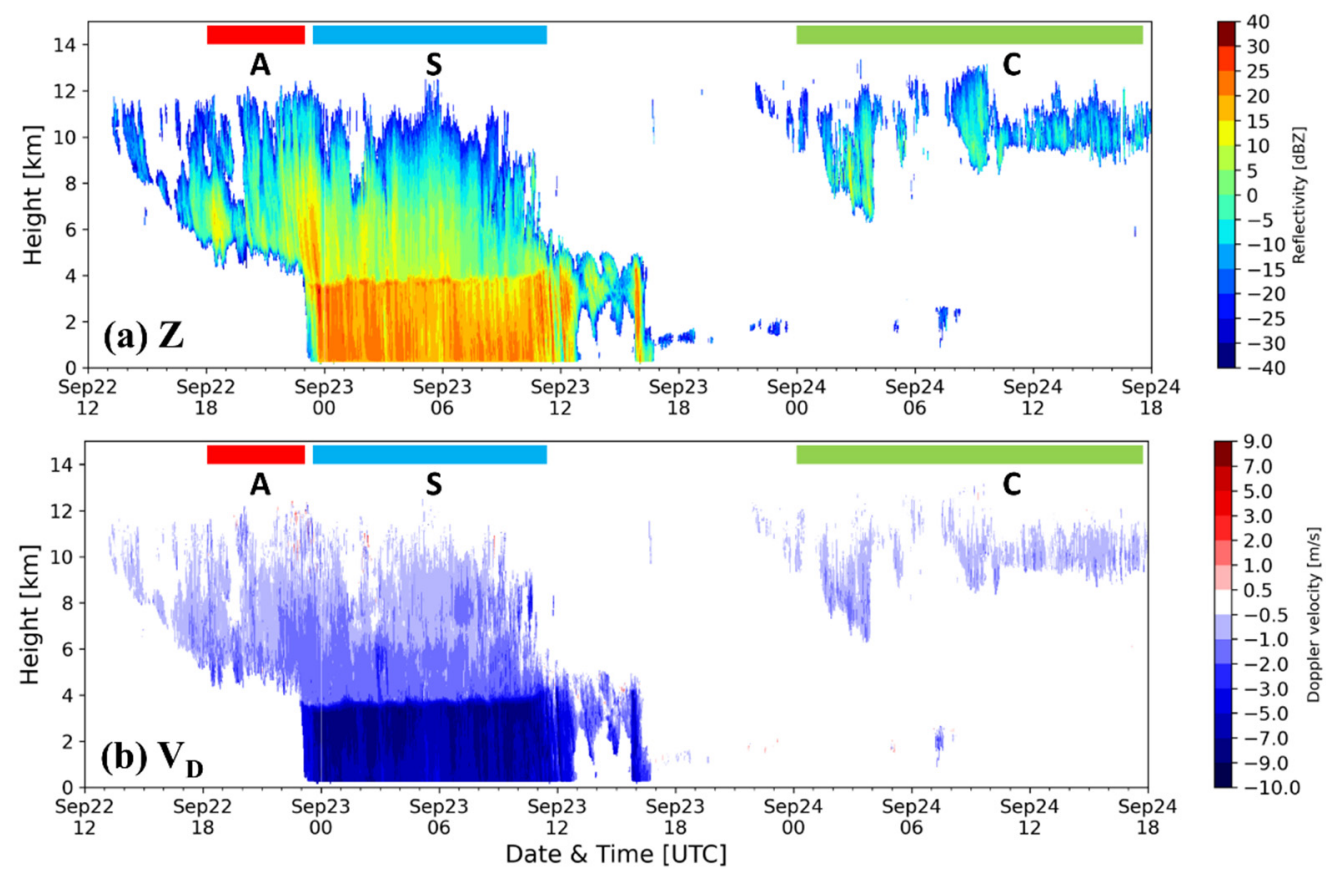

Figure 3. Time-height cross-sections of (a) $Z$ and (b) $V_{D}$ from 22 September to 24 September 2015. The color bar indicates the period of three types of ice clouds (C: cirrus, S: stratiform, and A: anvil).

The ice cloud cases were selected using $1 \mathrm{~min} Z$ profile data from June 2014 to October 2015. Table 2 provides information on the selected cases by ice cloud type. The cirrus cases occurred for a total of $309 \mathrm{~h}$ and cirrus echoes were distributed at a height of 6 to $14 \mathrm{~km}$, primarily concentrated in the 9 to $12 \mathrm{~km}$ area. We selected $90 \mathrm{~h}$ as the stratiform from stratiform precipitation cases with a bright band at a height of 4 to $5 \mathrm{~km}$. The anvil cases were represented by the thick cloud region that appeared before stratiform rainfall reached the ground over a total of $36.5 \mathrm{~h}$.

Table 2. Events of three types of ice clouds (C: cirrus, S: stratiform, and A: anvil) and their height ranges.

\begin{tabular}{cccccc}
\hline Case No. & Period & Height $\mathbf{( k m )}$ & Case No. & Period & Height $(\mathbf{k m})$ \\
\hline C1 & $13 / 06 / 2014,10-23$ UTC & $8-14$ & C18 & $18 / 09 / 2015,06-23$ UTC & $7-11$ \\
\hline C2 & $14 / 06 / 2014,00-23$ UTC & $7-13$ & C19 & $24 / 09 / 2015,00-18$ UTC & $6-14$ \\
\hline C3 & $26 / 06 / 2014,00-09$ UTC & $8-13$ & S1 & $05 / 07 / 2014,10-21$ UTC & $5-14$ \\
\hline C4 & $27 / 06 / 2014,05-23$ UTC & $6-12$ & S2 & $16 / 07 / 2014,08-17$ UTC & $5-13$ \\
\hline C5 & $08 / 07 / 2014,07-13$ UTC & $10-14$ & S3 & $12 / 10 / 2014,05-23$ UTC & $5-13$ \\
\hline C6 & $16 / 08 / 2014,00-11$ UTC & $10-13$ & S4 & $11 / 07 / 2015,04-23$ UTC & $5.5-14$ \\
\hline C7 & $30 / 08 / 2014,01-12$ UTC & $8-13$ & S5 & $23 / 09 / 2015,00-09$ UTC & $4.5-13$ \\
\hline
\end{tabular}


Table 2. Cont.

\begin{tabular}{cccccc}
\hline Case No. & Period & Height $(\mathbf{k m})$ & Case No. & Period & Height $(\mathbf{k m})$ \\
\hline C8 & $22 / 09 / 2014,10-21$ UTC & $11-15$ & S6 & $30 / 09 / 2015,00-18$ UTC & $5-14$ \\
\hline C9 & $25 / 09 / 2014,07-23$ UTC & $6-12$ & A1 & $16 / 06 / 2014,11-14$ UTC & $4-13$ \\
\hline C10 & $15 / 10 / 2014,15-21$ UTC & $8-12$ & A2 & $12 / 09 / 2014,00-02$ UTC & $4-12$ \\
\hline C11 & $15 / 03 / 2015,05-11$ UTC & $6-10$ & A3 & $12 / 10 / 2014,00-02 U T C$ & $4-13$ \\
\hline C12 & $03 / 04 / 2015,03-10$ UTC & $8-13$ & A4 & $22 / 05 / 2015,10-14$ UTC & $4-13$ \\
\hline C13 & $14 / 06 / 2015,07-21$ UTC & $8-13$ & A5 & $04 / 06 / 2015,14-15$ UTC & $4-13$ \\
\hline C14 & $23 / 06 / 2015,01-21$ UTC & $7-14$ & A6 & $17 / 06 / 2015,03-04$ UTC & $4-14$ \\
\hline C15 & $02 / 07 / 2015,00-09$ UTC & $10-14$ & A7 & $06 / 07 / 2015,04-10$ UTC & $4-14$ \\
\hline C16 & $09 / 07 / 2015,00-23$ UTC & $8-13$ & A8 & $16 / 09 / 2015,02-06$ UTC & $4-12$ \\
\hline C17 & $09 / 08 / 2015,00-23$ UTC & $6-13$ & A9 & $22 / 09 / 2015,17-22$ UTC & $4-13$ \\
\hline
\end{tabular}

\subsection{Estimation of Terminal Velocity and Vertical Air Motion}

The cloud radar cannot directly measure the mean terminal fall velocity, $V_{t}$, of hydrometeors within the observational volume. The observed $V_{D}$ is the sum of $V_{t}$ and the vertical air motion, $V_{\text {air }}$, as the following equation:

$$
V_{D}\left(\mathrm{~m} \mathrm{~s}^{-1}\right)=V_{t}+V_{\text {air }}
$$

The observed $V_{D}$ is contributed by the sedimentation of ice particles. The effect of $V_{\text {air }}$ is reflected on $V_{D}$ and cannot be ignored in the ice cloud with respect to the $V_{t}$ of ice particles. Thus, $V_{\text {air }}$ is derived from Equation (1) by applying estimated $V_{t}$ and observed $V_{D}$. $V_{t}$ can be estimated by using a power-law relationship between $Z$ and $V_{t}$ as in Equation (2).

$$
V_{t}\left(\mathrm{~m} \mathrm{~s}^{-1}\right)=a Z^{b}
$$

where $\mathrm{Z}$ is measured with a linear unit $\left(\mathrm{mm}^{6} \mathrm{~m}^{-3}\right) . V_{\text {air }}$ should be negligible from the averaged $V_{D}$ over a longer time period, and averaged $V_{D}$ should be identical to the averaged $V_{t}[10,20,26]$. The $V_{t}-Z$ relationship was then derived using the observed averaged $Z$ and $V_{D}$ during a given time period. The time average was tested in increments of 5 , $10,20,30$, and $60 \mathrm{~min}$. Here, $Z$ was a linear unit and only positive velocity was used. $V_{t}$ was calculated from the observed $Z$ using a pre-determined $V_{t}-Z$ relationship for each type of ice cloud. $V_{\text {air }}$ was then estimated from the calculated $V_{t}$ and observed $V_{D}$ using Equation (1).

\section{Results}

\subsection{Properties of Radar Parameters}

The frequency distributions of $Z, V_{D}$, and SW were examined for the classified ice clouds. Figure 4 shows the histograms of radar parameters by ice cloud type. The bin size of the histogram was $2 \mathrm{dBZ}$ for $Z, 0.2 \mathrm{~m} \mathrm{~s}^{-1}$ for $V_{D}$, and $0.02 \mathrm{~m} \mathrm{~s}^{-1}$ for SW. The frequency was normalized with the total frequency of each type. The $Z$ of the anvil and stratiform were broadly distributed from -30 to $20 \mathrm{dBZ}$, whereas that of cirrus had a narrow distribution of $Z$ from -30 to $5 \mathrm{dBZ}$. The $Z$ distributions of the anvil and stratiform displayed similar features, but the $Z$ of the anvil was larger than that of stratiform. In addition, the second peak in anvil and stratiform coincided with the first peak in cirrus. The velocity distribution of cirrus was narrow with a peak of $-0.6 \mathrm{~m} \mathrm{~s}^{-1}$ that showed smaller absolute values than those of the peaks of the anvil and stratiform velocities $\left(-1.2 \mathrm{~m} \mathrm{~s}^{-1}\right)$. Although anvil had a larger $Z$, it showed a smaller falling velocity (smaller negative values) than that of 
stratiform. The peak in SW distribution of cirrus was $0.04 \mathrm{~m} \mathrm{~s}^{-1}$, while that in stratiform was the largest at $0.14 \mathrm{~m} \mathrm{~s}^{-1}$.
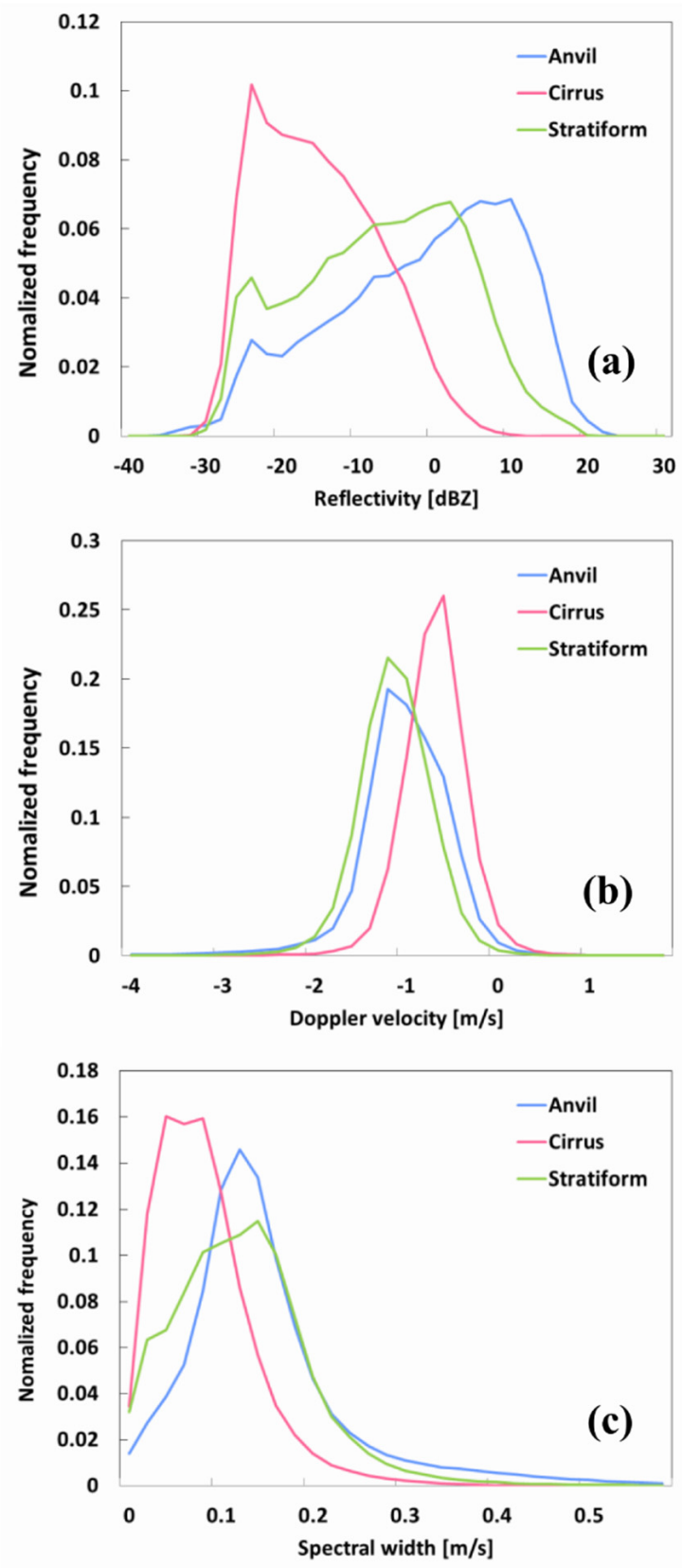

Figure 4. Histograms of (a) Z, (b) $V_{D}$, and (c) SW by ice cloud type (blue: anvil, pink: cirrus, and green: stratiform).

To obtain detailed distributions of radar parameters by ice cloud type, the histograms were calculated in different intervals of cloud height (Figure 5). The cirrus within a height of 10 to $12 \mathrm{~km}$ showed the highest frequency at $-25 \mathrm{dBZ}$ for $Z,-0.6 \mathrm{~m} \mathrm{~s}^{-1}$ for $V_{D}$, and $0.03 \mathrm{~m} \mathrm{~s}^{-1}$ for SW. This result was consistent with that of the work conducted by Ye et al. [18] since over $60 \%$ of cirrus cases were observed during the summer season (June to July). The shape of $Z$ distribution in a cirrus that occurred at a height of 12 to $15 \mathrm{~km}$ was similar to that in cirrus at a height of 10 to $12 \mathrm{~km}$. In contrast, the cirrus occurring at a height from 8 to $10 \mathrm{~km}$ had a right-skewed distribution with a peak at $-7 \mathrm{dBZ}$. In stratiform and anvil types, the highest frequencies occurred at a height range of 6 to $8 \mathrm{~km}$, and the peaks of histograms moved to larger $Z$ and large negative (downward) velocity 
with decreasing heights, indicating the downward growth of precipitation. The mode of SW distributions systematically moved to larger values with a decrease in height (notably less in cirrus). This is likely an indication of the spread of particle size distribution toward the ground due to their steady growth as indicated by the change in $Z$ mode.

(a) Cirrus

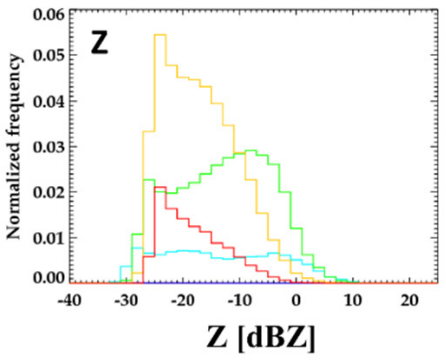

(b) Stratiform

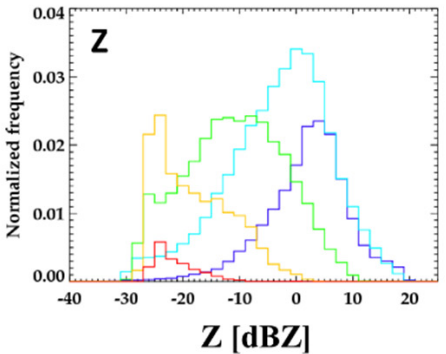

(c) Anvil

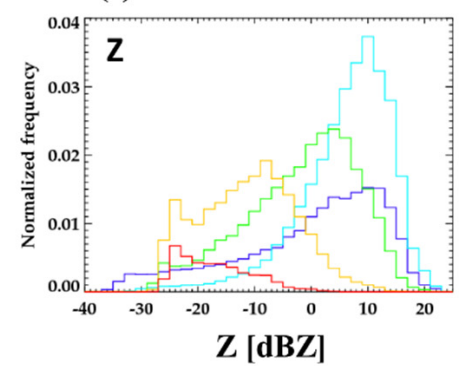

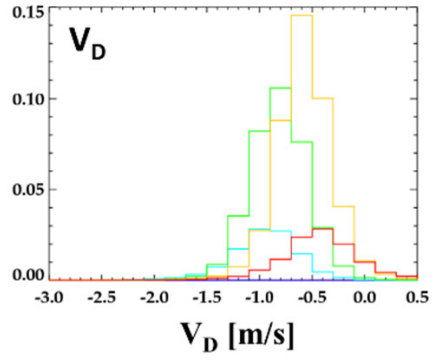
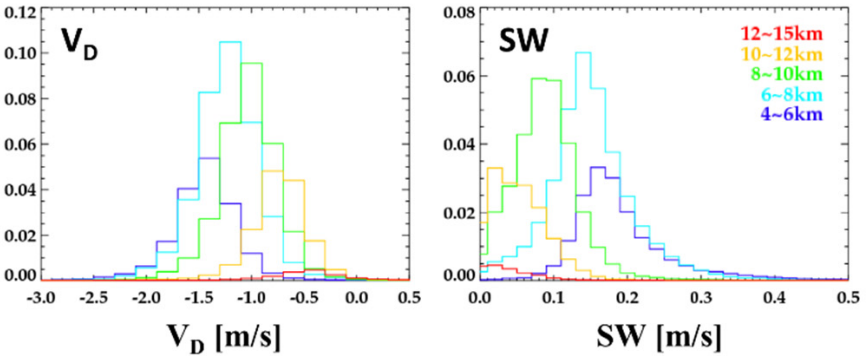

$\mathrm{SW}[\mathrm{m} / \mathrm{s}]$
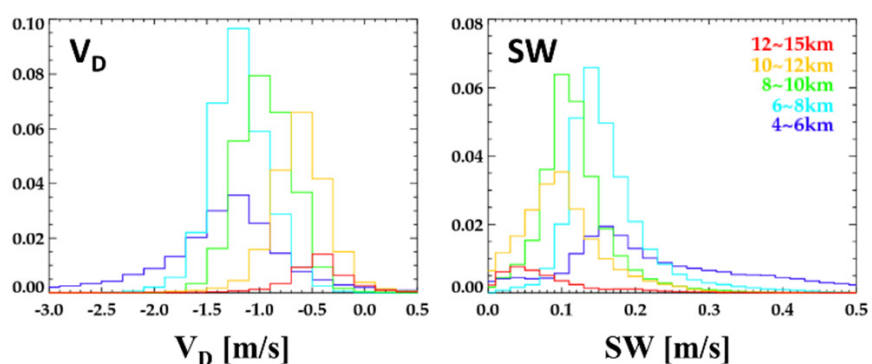

Figure 5. Histograms of $Z, V_{D}$, and $\mathrm{SW}$ for (a) cirrus, (b) stratiform, and (c) anvil with various cloud heights (blue: 4-6 km, cyan: 6-8 km, green: 8-10 km, yellow: 10-12 km, and red: $12-15 \mathrm{~km}$ ).

Figure 6 shows contoured frequency by altitude diagrams (CFAD) of $Z, V_{D}$, and $\mathrm{SW}$ for the three ice cloud types. Cirrus typically occurred at a height range from 9 to $12 \mathrm{~km}$. The stratiform and anvil type clouds showed two modes at height ranges of 10-12 km (similar to cirrus) and 5-9 km, respectively. This indicates the potential seeder-feeder effect in stratiform and anvil. The significant growth of $Z$ and $V_{D}$ appeared in the layer from 8 to $10 \mathrm{~km}$ for all types of ice clouds. However, the $V_{D}$ of stratiform was nearly constant near a height of 7 to $8 \mathrm{~km}$ and seems to be an elongated "S" shape. In addition, SW rapidly increased in this layer due to the broadening of the power spectrum. Thus, this " $\mathrm{S}$ " shape of $V_{D}$ with an increase in $Z$ can be interpreted as either (1) the existence of an upward air motion with induced turbulence or (2) broadening of snow particle size distributions due to an increased number concentration of smaller particles. 
(a) Cirrus

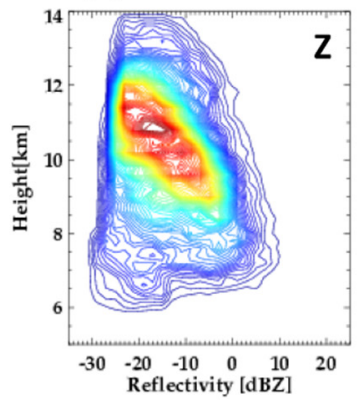

(b) Stratiform

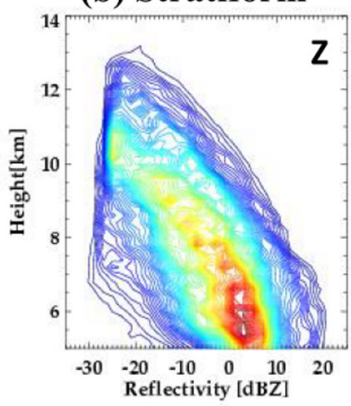

(c) Anvil

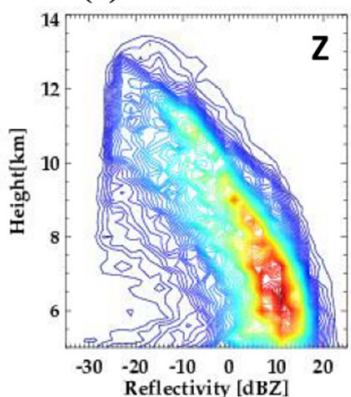

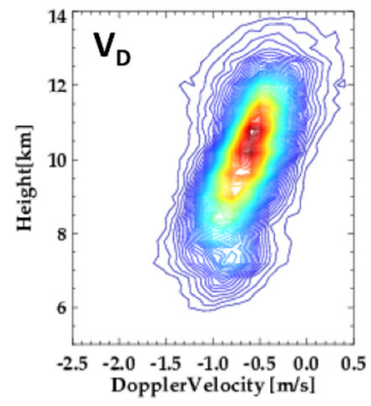
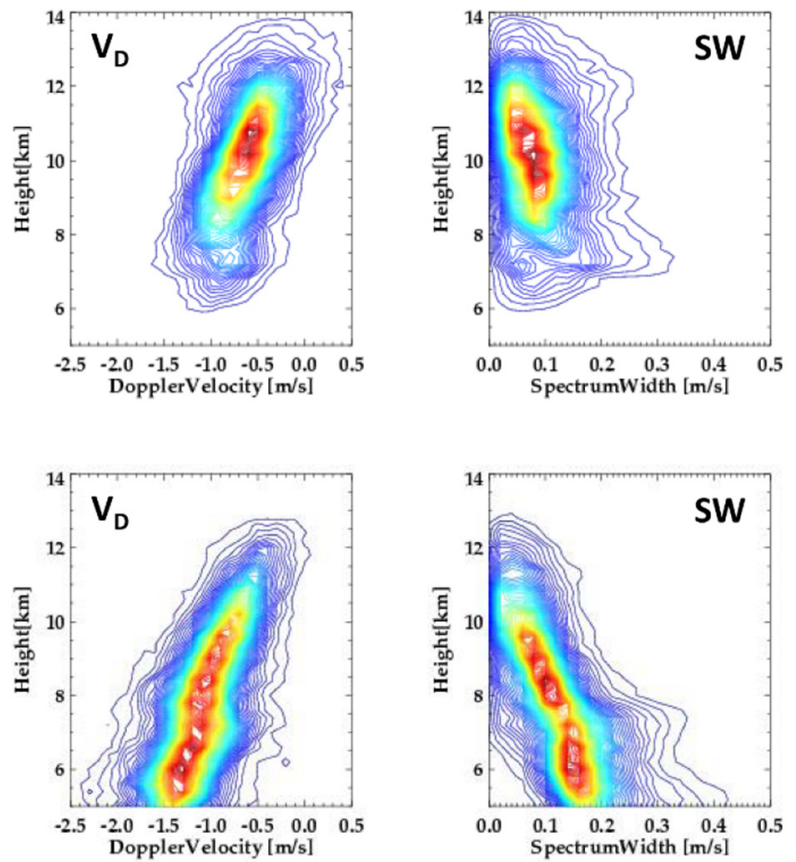

100

90

80

70

60

$50 \stackrel{\text { ปे }}{0}$

20

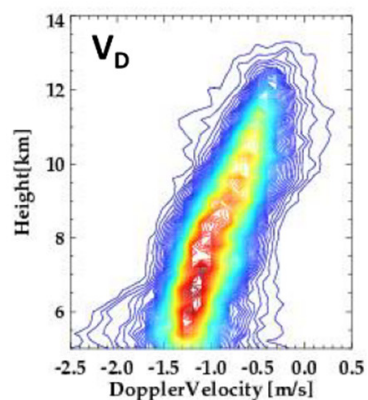

Figure 6. Contoured frequency by altitude diagrams (CFADs) of $Z, V_{D}$, and SW for ice cloud types: (a) cirrus, (b) stratiform, and (c) anvil.

The mean vertical profiles of the radar parameters are shown in Figure 7. The $Z$ slope is related to ice cloud growth. $Z$ in general increased with increasing $V_{D}$, and $S W$, indicating general growth of ice particles. The mean $Z$ for stratiform and anvil increased with a similar slope at the height range of 8 to $11 \mathrm{~km}$, but the averaged $Z$ of the anvil was larger than the $Z$ of stratiform throughout the entire altitude. The $V_{D}$ profiles of cirrus and anvil were quite similar in the layer of $9-12 \mathrm{~km}$ and then separated below the layer due to a rapid reduction in $Z$ in cirrus (that is, evaporation of ice particles). However, the falling velocity (negative $V_{D}$ ) profiles of anvil were smaller than those of stratiform. In addition, the SW of the anvil was the largest due to the diverse size and velocity of ice particles. This indicates that anvil is composed of a lower density and larger sizes of ice particles than those of stratiform. One of the outstanding features in the averaged $V_{D}$ profile was the elongated "S" shape with reduced $V_{D}$ values in the layer of $7-8 \mathrm{~km}$. It is notable that SW in stratiform and anvil dramatically increased at the 7-8 km height. 
(a) Reflectivity

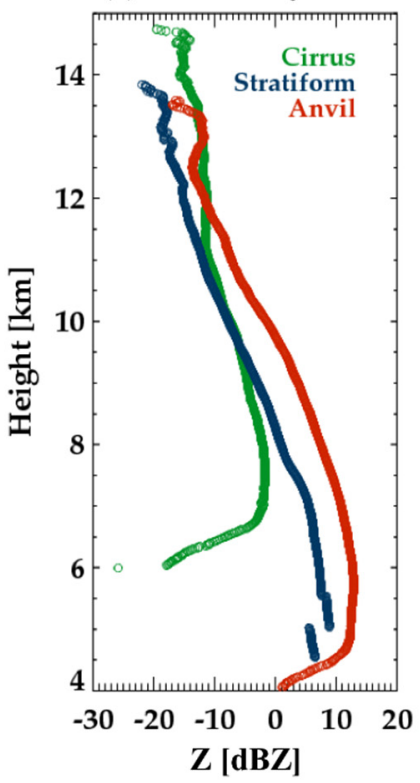

(b) Doppler velocity

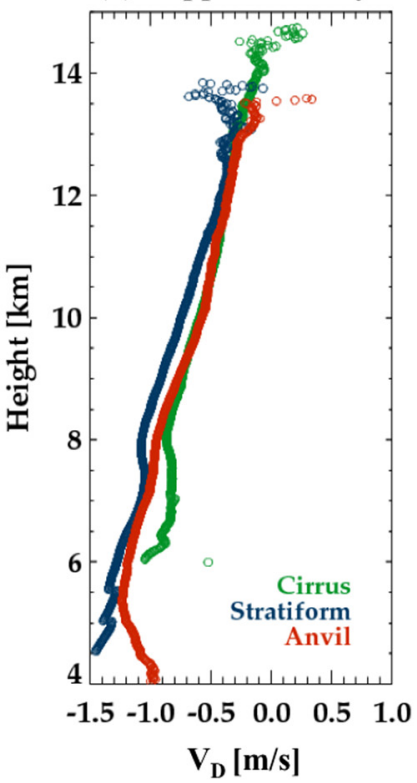

(c) Spectrum width

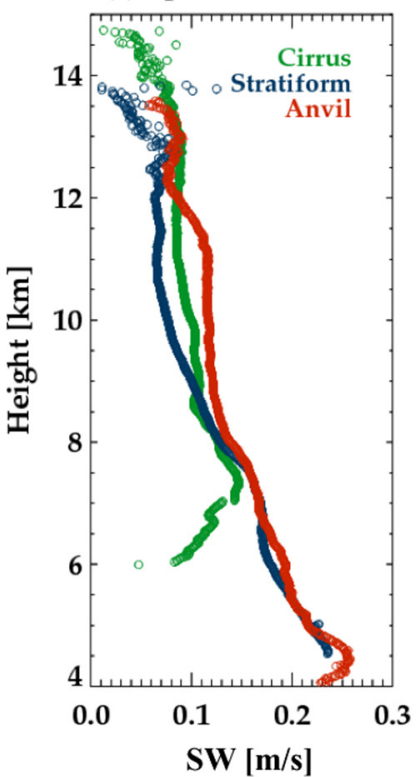

Figure 7. Mean vertical profiles of (a) $Z,(\mathbf{b}) V_{D}$, and (c) SW for three types of ice clouds. Green: cirrus, blue: stratiform, and red: anvil.

\subsection{Estimation of Terminal Velocity and Vertical Air Motion}

When a $V_{t}-Z$ relationship was calculated by the various temporal average intervals, the coefficient $a$ and exponent $b$ changed depending on averaging time and ice cloud types. In the cirrus case on 25 September 2014, the coefficient slightly decreased from 0.794 to 0.779 with an increase in the average time by up to $20 \mathrm{~min}$ and then increased from 0.779 to 0.816 at an average time longer than $20 \mathrm{~min}$ (Figure 8). The exponent increased from 0.104 to 0.138 with an average time of 5-60 $\mathrm{min}$. In contrast, the coefficients decreased from 0.848 to 0.835 with an increase in average time for the anvil case on 16 June 2014 (not shown). As the average time increased, smaller-scale variabilities were eliminated, and only mean characteristics remained. It was necessary to select the average time in which the coefficient and exponent representing the properties of ice clouds did not significantly change. Protat and Williams [20] found that the error of estimated terminal fall velocity can be most reduced when the average time is set at $20 \mathrm{~min}$. In addition, Matrosov et al. [13] and Delanoë et al. [10] proposed that it is possible to approximate $V_{D}$ as the $V_{t}$ in this time average since $V_{\text {air }}$ can be neglected with an average of $20 \mathrm{~min}$. Therefore, the average time for the calculation of the $V_{t}-Z$ relationship was set as $20 \mathrm{~min}$.

The $V_{t}-Z$ relationships were derived for all ice cloud cases (Figure 9). The mean coefficient and mean exponent for cirrus (filled green dot) were 0.65 (0.29 to 1.5) and 0.09 $(-0.04$ to 0.17$)$, respectively. The cirrus clouds had larger differences in $Z$ and $V_{t}$ depending on the height of the cloud echo and the wide distribution of the values of coefficients and exponents. As cloud height decreased, the coefficient and exponent became larger (Figure 9c,d). Although cirrus showed a wide variation of coefficients and exponents, the variation of $V_{t}$ in cirrus was relatively small with $Z$ varying (Figure $9 \mathrm{~b}$ ). These results were similar to those of previous studies on cirrus cloud [20,26]. According to Kalesse et al. [26], the empirical relationship relates dominant microphysical processes in different parts of ice clouds, and exponent $b$ can be explained in terms of moments of particle size distributions. In addition, they showed that a negative (or close to zero) exponent $b$ near the cloud top indicates a rapid increase in number concentration (low moment) rather than reflectivity (high moment). This coefficient was the smallest in cirrus. 

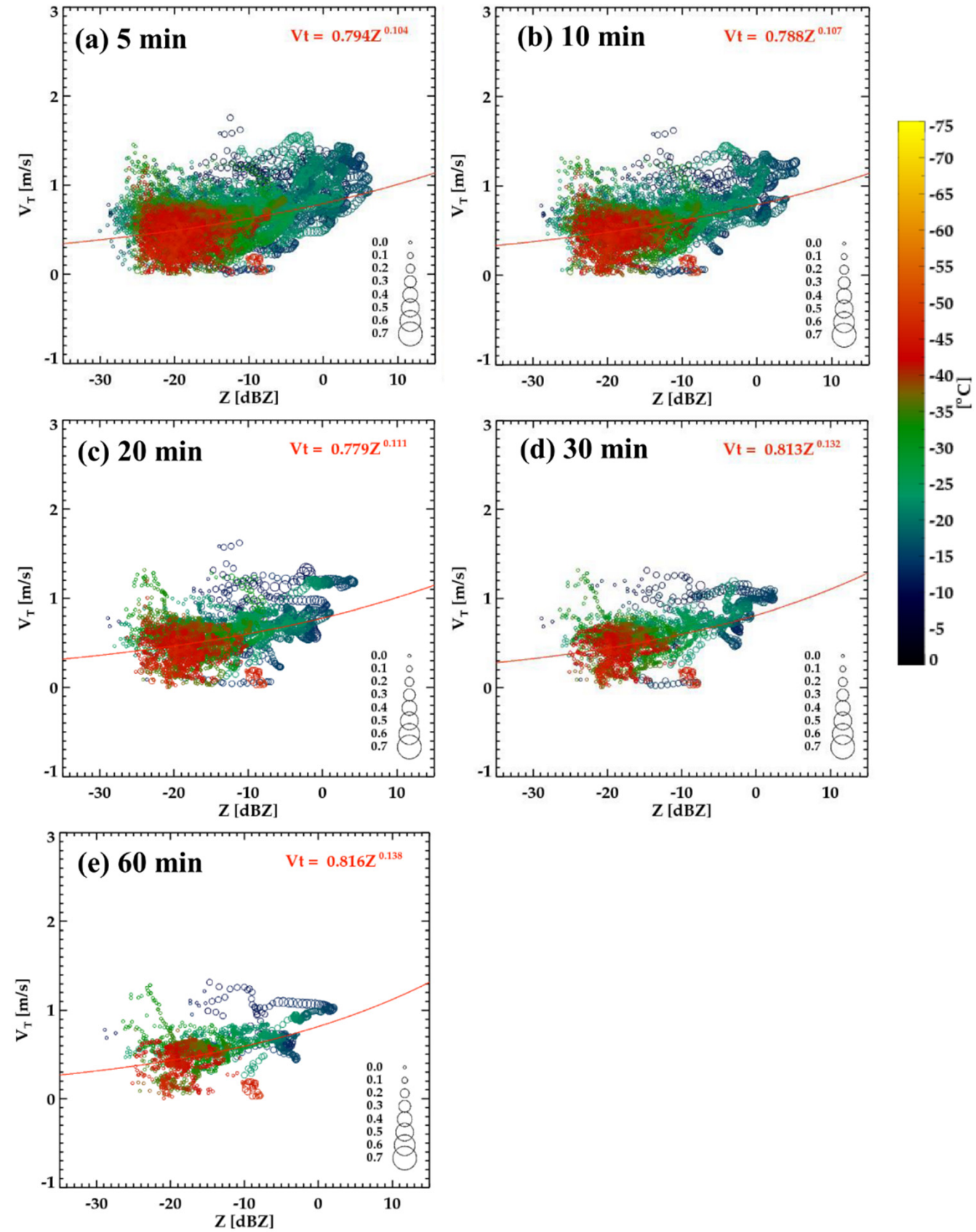

Figure 8. Scatterplots of terminal velocity $\left(V_{t}\right)$ as a function of $Z$ for a case of cirrus on 25 September 2014 as a function of average window sizes: (a) $5 \mathrm{~min}$, (b) $10 \mathrm{~min}$, (c) $20 \mathrm{~min}$, (d) $30 \mathrm{~min}$, and (e) $60 \mathrm{~min}$. The red lines are fitted $V_{t}-Z$ relationships. The circles indicate SW, and the color is atmospheric temperature from sounding measurements.

For stratiform cases, the coefficient $a$ was from 0.95 to 1.37 (mean of 1.07) and the exponent $b$ was from 0.08 to 0.16 (mean of 0.12 ). The coefficients and exponents of anvil cases were from 0.63 to 0.90 and from 0.12 to 0.19 , respectively. With the same $Z$, the $V_{t}$ of stratiform was always higher than the $V_{t}$ of the anvil. However, anvil had a larger $b$ than that of the exponent of stratiform, indicating that the $V_{t}$ of anvil increased more rapidly than that of stratiform as $Z$ increased. This implies that the density of anvil increased more quickly than that of stratiform for the same $Z$ increment [31,32]. 

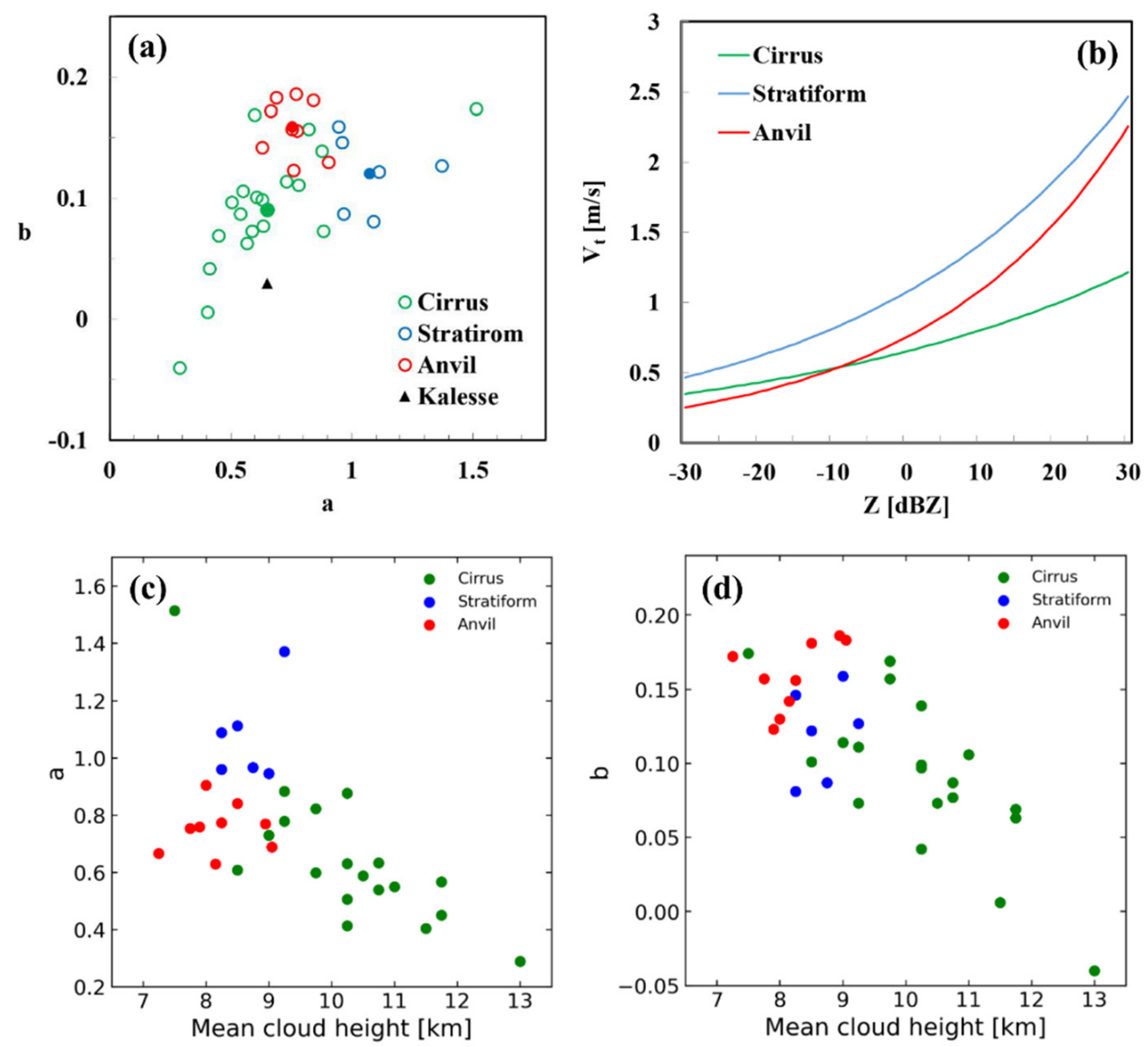

Figure 9. (a) Scatterplot of coefficient $a$ and exponent $b$ of $V_{t}-Z$ relationships for ice cloud cases. The colored circles indicate ice cloud types (green: cirrus, blue: stratiform, and red: anvil). The black triangle represents the coefficient and exponent from Kalesse et al. [26]. (b) $V_{t}-Z$ relationships for ice cloud types. Scatterplots of mean cloud height and (c) coefficient $a$ and (d) exponent $b$ of $V_{t}-Z$ relationships for ice cloud cases.

$V_{t}$ was calculated from the observed $Z$ using pre-determined $V_{t}-Z$ relationships by ice cloud types, and $V_{\text {air }}$ was then estimated by comparing $V_{D}$ with derived $V_{t}$. Figures 10-12 show the time-height cross-section of observed $Z$ and $V_{D}$ as well as the estimated $V_{t}$ and $V_{\text {air }}$. In the case of cirrus on 9 August 2015 (Figure 10), $Z$ increased from -25 to $5 \mathrm{dBZ}$ and $V_{D}$ increased from 0 to $-1.5 \mathrm{~m} \mathrm{~s}^{-1}$ as the $V_{t}$ of ice particles increased. Interestingly, the vertical and temporal structure of $V_{D}$ is much smaller than that of $Z$ and $V_{t}$, which is due to the added smaller scale variation in vertical air motion.

According to Protat and Williams [20], the $V_{t}-Z$ relationship technique has a high level of accuracy, in which the residual between retrieved $V_{t}$ and reference $V_{t}$ is less than $0.1 \mathrm{~m} \mathrm{~s}^{-1}$ above a height of $9 \mathrm{~km}$. Given this error, the retrieval technique of $V_{\text {air }}$ in this study will contribute to understanding the microphysical and dynamical processes in the ice clouds. $V_{\text {air }}$ had an upward air motion up to $0.4 \mathrm{~m} \mathrm{~s}^{-1}$ in the upper part of the cloud where $V_{D}$ was small and the estimated $V_{t}$ ranged from -0.8 to $-0.4 \mathrm{~m} \mathrm{~s}^{-1}$. However, $V_{\text {air }}$ in the lower part of the cloud appeared to be a downward air motion from -0.8 to $0 \mathrm{~m} \mathrm{~s}^{-1}$. The bottom part of the cloud was repeatedly modulated by upward and downward motions. 

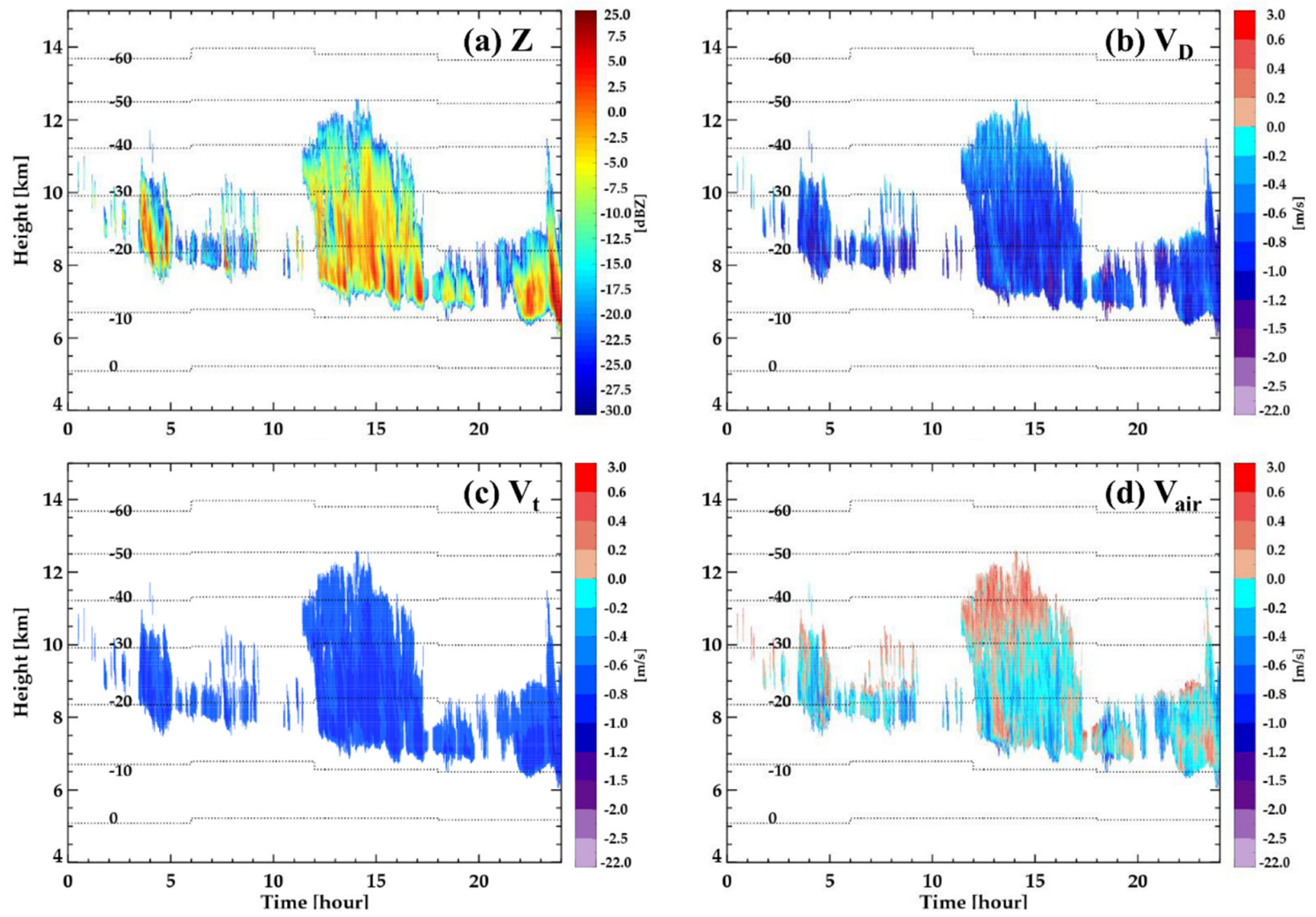

Figure 10. Time-height cross-sections of (a) observed $Z$, (b) observed $V_{D}$, (c) $V_{t}$ retrieved from $V_{t}-Z$ relationship of cirrus, and $(\mathbf{d})$ retrieved vertical air motion $\left(V_{\text {air }}\right)$ of a case of cirrus on 9 August 2015. Dotted line is temperature from sounding data.
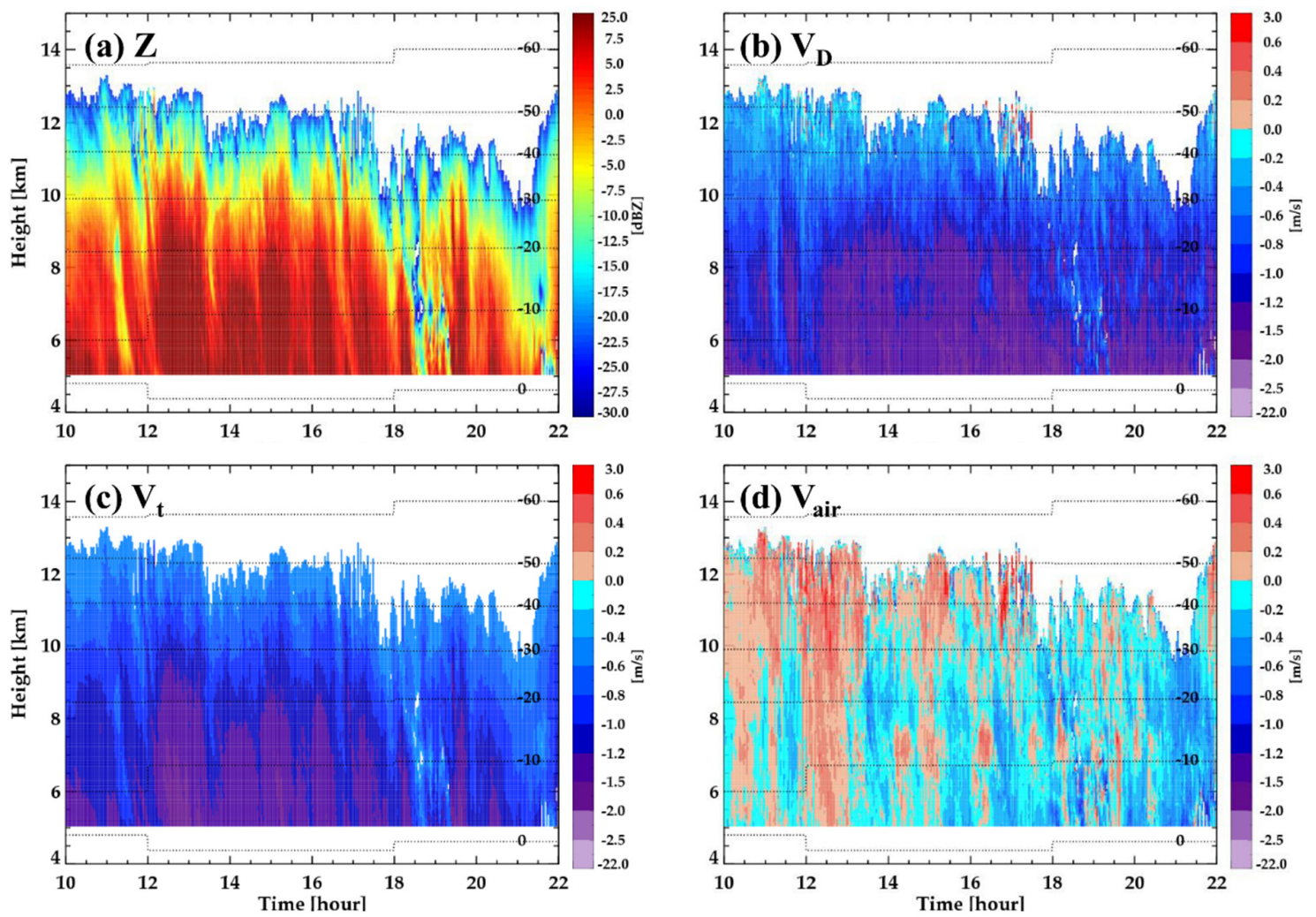

Figure 11. Time-height cross-sections of (a) observed $Z$, (b) observed $V_{D}$, (c) $V_{t}$ retrieved from $V_{t}-Z$ relationship of stratiform, and (d) retrieved $V_{\text {air }}$ of a case of stratiform on 5 July 2014. Dotted line is temperature from sounding data. 

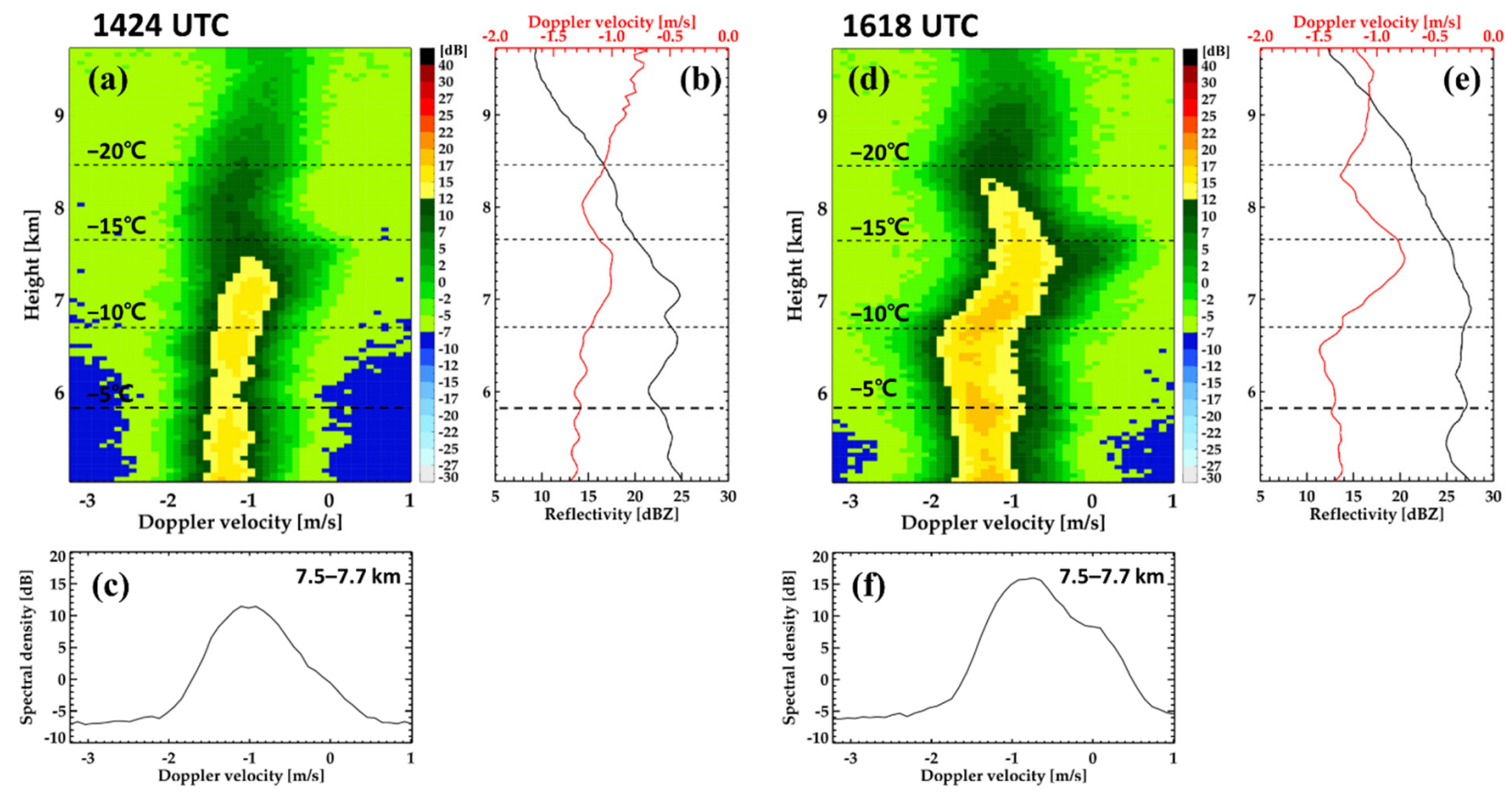

Figure 12. (a,d) Doppler power spectra at different heights, (b,e) vertical profiles of $Z$ and $V_{D}$, and (c,f) averaged Doppler power spectrum between 7.5-7.7 km observed from vertically pointing X-band radar at 1424 UTC and 1618 UTC on 5 July 2014. Positive (negative) velocity indicates upward (downward) motion. Dashed lines indicate temperatures from sounding data.

The case of stratiform on 5 July 2014 developed vertically to a height of $13 \mathrm{~km}$ (Figure 11). A dramatic growth appeared with an increase in $Z$ of about $8 \mathrm{~dB} \mathrm{~km}^{-1}$ and an increase in $V_{t}$ of about $0.3 \mathrm{~m} \mathrm{~s}^{-1} \mathrm{~km}^{-1}$ at the height of $10-13 \mathrm{~km}$. Strong upward air motions (up to $1.5 \mathrm{~m} \mathrm{~s}^{-1}$ ) appeared in this layer. Strong $Z$ was prominent and vertically well developed at 1200-1330 UTC. This is related to a vertically stacked updraft with strong hot spots of $V_{\text {air }}$ in the top of the precipitation system. There exists a significant reduction in $V_{D}$ in the layer with a height of $7-8 \mathrm{~km}\left(-17--15^{\circ} \mathrm{C}\right)$ (Figure 11b). This is consistent with the mean vertical profiles of $V_{D}$ in Figure $7 \mathrm{~b}$. This appeared as the layer of upward motion with some periodicity (Figure 11d). Similar characteristics appeared in different stratiform cases, leading to average statistical characteristics (shown below).

To investigate this unique feature in detail, we examined the Doppler power spectra of vertically pointing X-band radar (VertiX, detail specification in [18]). When upward air motion appeared at a height of 7-8 km, the Doppler spectra at a height of 7.5-7.7 km (layer near $-15^{\circ} \mathrm{C}$ ) showed bi-modality with peaks at $-1.0--0.8$ and $-0.2-0.2 \mathrm{~m} \mathrm{~s}^{-1}$ (Figure 12). The second peaks at a smaller fall velocity (smaller particles) became more pronounced from 1424 UTC to 1618 UTC on 5 July 2014. In addition, the $V_{D}(Z)$ of the first peak decreased (increased) from 9.5 to $8.4 \mathrm{~km}$, indicating the growth of larger ice particles. Then, $V_{D}$ increased from a height of 8.4 to $7.3 \mathrm{~km}$, where the second peak completely merged with the first peak. This increase was induced by the upward air motion. Furthermore, as shown by the second peak, numerous smaller ice particles of low $V_{t}$ were produced in this layer, grew, and merged afterward with existing larger ice particles. This layer had a temperature range of $-16^{\circ} \mathrm{C}$ to $-13^{\circ} \mathrm{C}$, which was favorable for the growth of pristine crystals to planar types [33-36]. Thus, further investigation of the physical causes of upward motion and the following microphysical processes with dual-polarimetric radar data and snow habits from aircraft in situ measurements is recommended.

In the case of anvil on 16 July 2014, the $Z$ and $V_{D}$ increased with a decrease in height and showed fall streaks of cloud particles (Figure 13). $V_{t}$ also showed a clear fall streak below $8 \mathrm{~km}$. A rapid increase in $Z$ was observed in the layer of $7-8 \mathrm{~km}$, which was consistent with the rapid decrease in $V_{D}$ at 1100-1300 UTC. The $V_{\text {air }}$ showed positive values (upward) 
in this layer and the upper part of this system. After 13 UTC, the upward air motion appeared in the entire clouds, and the rapid growth started from the upper layers.
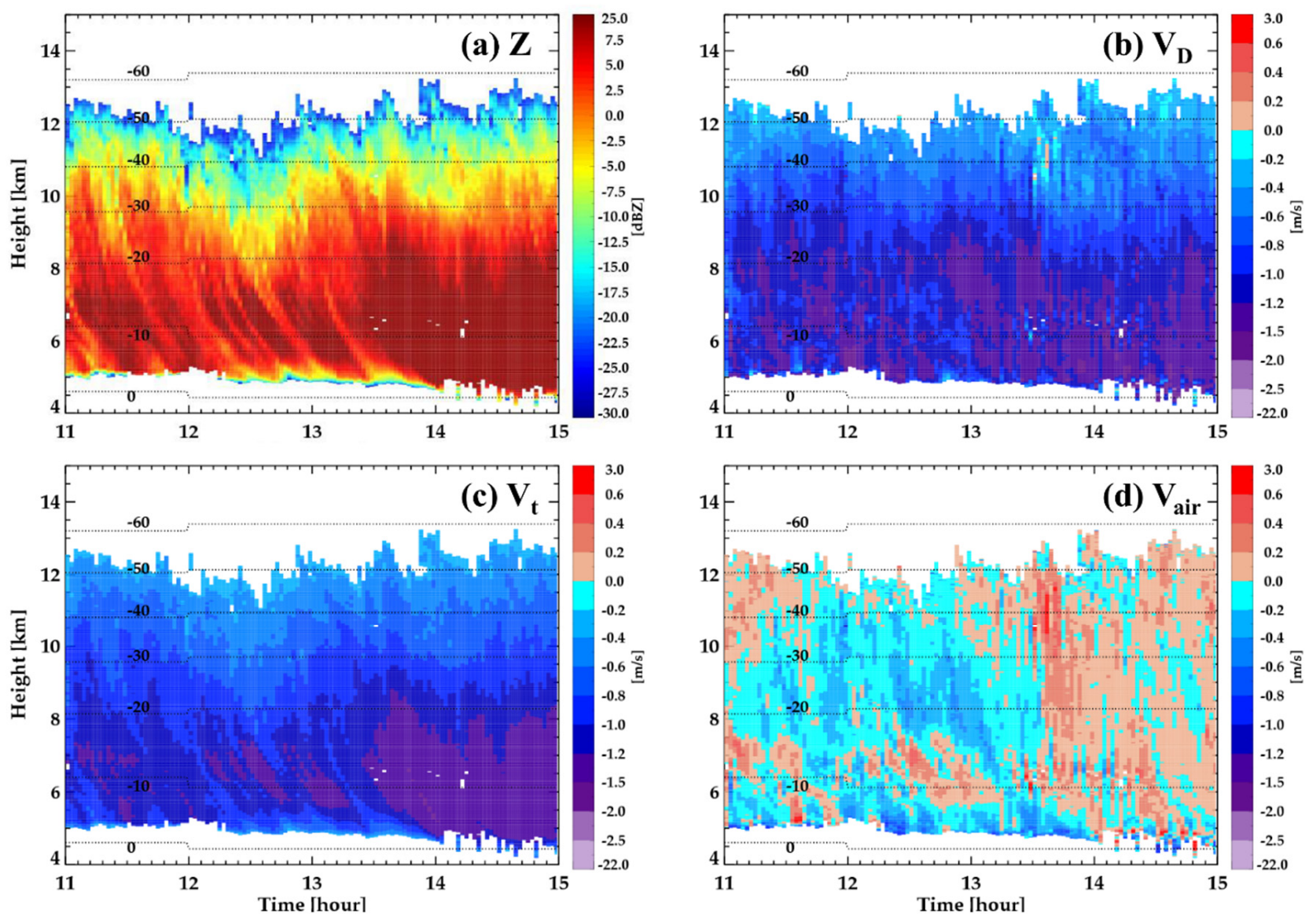

Figure 13. Time-height cross-sections of (a) observed $Z,(\mathbf{b})$ observed $V_{D}$, (c) $V_{t}$ retrieved from $V_{t}-Z$ relationship of anvil, and (d) retrieved $V_{\text {air }}$ of a case of anvil on 16 June 2014. Dotted line is temperature from sounding data.

The same retrieval procedure of $V_{t}$ and $V_{\text {air }}$ for all cases (Table 2) was repeated, and the averaged $V_{D}, V_{t}$, and $V_{\text {air }}$ for all cases are shown in Figure 14 . In cirrus, average $V_{t}$ showed the smallest values (of -0.7 to $-0.4 \mathrm{~m} \mathrm{~s}^{-1}$ ), although its $V_{D}$ was similar to that of the anvil, which is due to the slow growth of particles (Figure 7a) and a smaller slope in the $V_{t}-Z$ relationship (Figure $9 \mathrm{~b}$ ). $V_{t}$ showed dramatic increases (from -0.5 to $-1.1 \mathrm{~m} \mathrm{~s}^{-1}$ ) in anvil due to larger values of $Z$, as shown in Figure 7a. The $V_{t}$ values of the stratiform were the largest (from -0.7 to $-1.2 \mathrm{~m} \mathrm{~s}^{-1}$ ). The smallest mean upward air motion of less than $0.03 \mathrm{~m} \mathrm{~s}^{-1}$ appeared in the top layer above $11 \mathrm{~km}$ in cirrus and the downward motion was dominant below this layer. The average $V_{\text {air }}$ of stratiform and anvil showed a similar trend: upward motion in the top layer, followed downward motion below, dramatic upward motion in the layer with a height of $7 \mathrm{~km}$, and then downward motion below. In particular, the elongated "S" shape of the average $V_{\text {air }}$ was remarkable, with dramatic upward motion in the layer at around $7 \mathrm{~km}$, particularly in the case of stratiform. 
(a) Doppler velocity

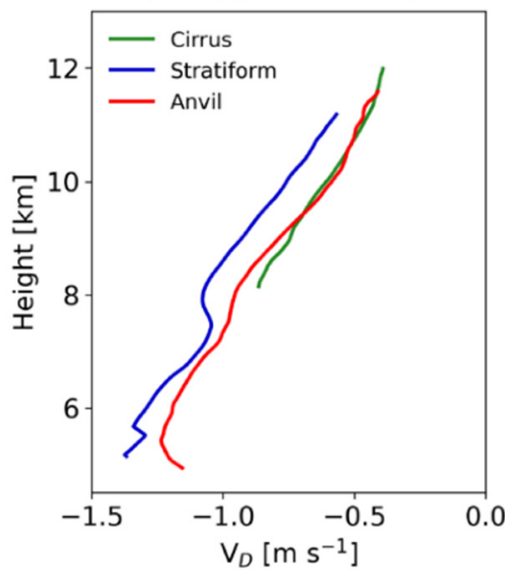

(b) Terminal velocity

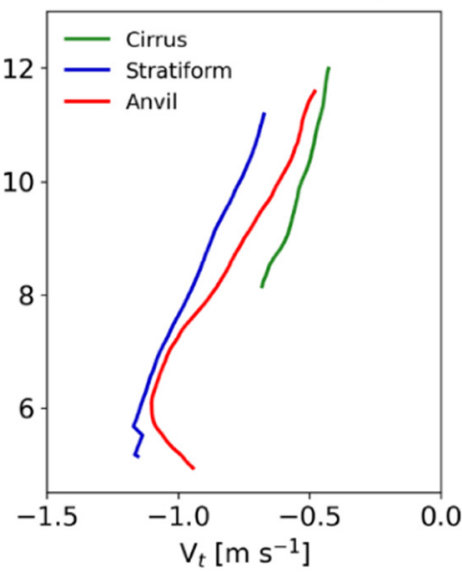

(c) Vertical air motion

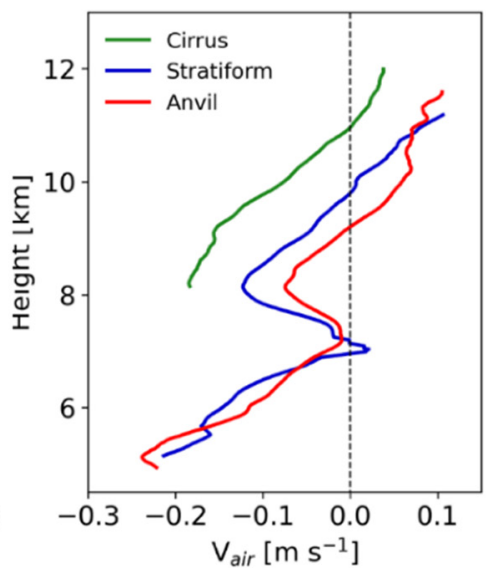

Figure 14. Averaged profiles of (a) $V_{D}$, (b) $V_{t}$, and (c) $V_{\text {air }}$ for cirrus, stratiform, and anvil cases.

$V_{\text {air }}$ was further examined via its CFAD, as shown in Figure 15. Stratiform and anvil showed the clear feature of an elongated "S" shape with a significant upward movement in the layer of $7 \mathrm{~km}$. $V_{\text {air }}$ reached $0.5 \mathrm{~m} \mathrm{~s}^{-1}$ for some cases in this layer. The physical reasons for this upward motion layer, which corresponds to about $-15^{\circ} \mathrm{C}$, are yet to be determined. In addition, the quantile range of $V_{\text {air }}$ was the largest in the case of stratiform, indicating the existence of active dynamical processes.

(a) Cirrus

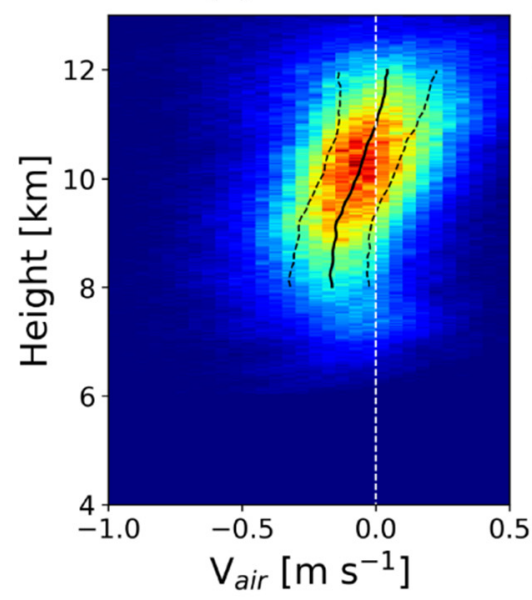

(b) Stratiform

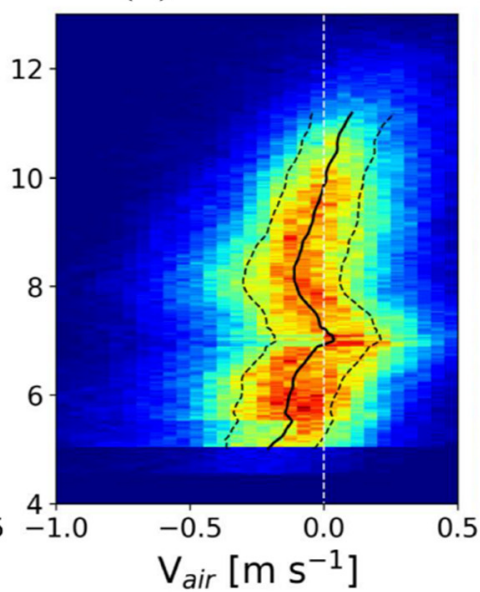

(c) Anvil

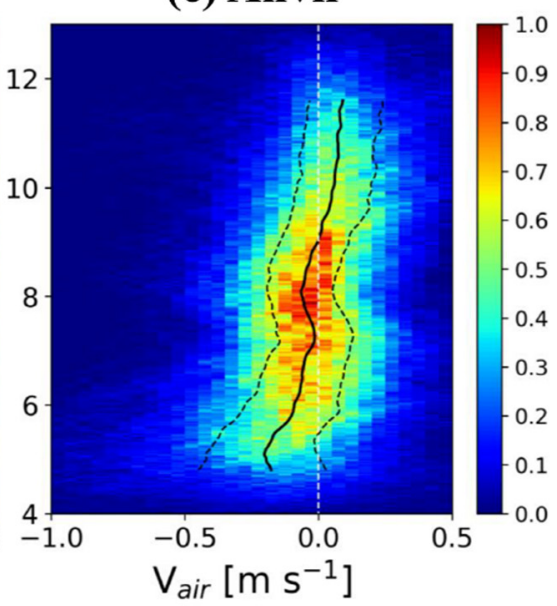

Figure 15. Contoured frequency by altitude diagrams (CFADs) of $V_{\text {air }}$ for different ice cloud types: (a) cirrus, (b) stratiform, and (c) anvil cases. The median and quantiles ( $25 \%$ and $75 \%)$ are shown in the solid and dashed lines.

\subsection{Variability of Vertical Air Motion in a Case of Kelvin-Helmholtz (K-H) Wave on 18 June 2013}

The estimations of $V_{t}$ and $V_{\text {air }}$ were performed for a cloud case associated with a heavy precipitation system from 0400 to 0440 UTC on 18 June 2013 (Figure 16). This system was associated with the stationary front, Changma front. The melting layer of precipitation occurring at 4.5-5 km showed a rapid increase in $Z$ and $V_{D}$. Above the melting layer, the large variability of $V_{D}$ occurred, in particular, a smaller scale structure in the layer of 5-6 km. The positive $V_{D}$ (warm colors and upward motion) also appeared in the layer of 6 to $7.5 \mathrm{~km}$ at $0432 \mathrm{UTC}$. As a result of estimations of $V_{t}$ and $V_{\text {air }}, V_{t}$ gradually increased with a decrease in height, whereas $V_{\text {air }}$ appeared with large variability in time and height. 

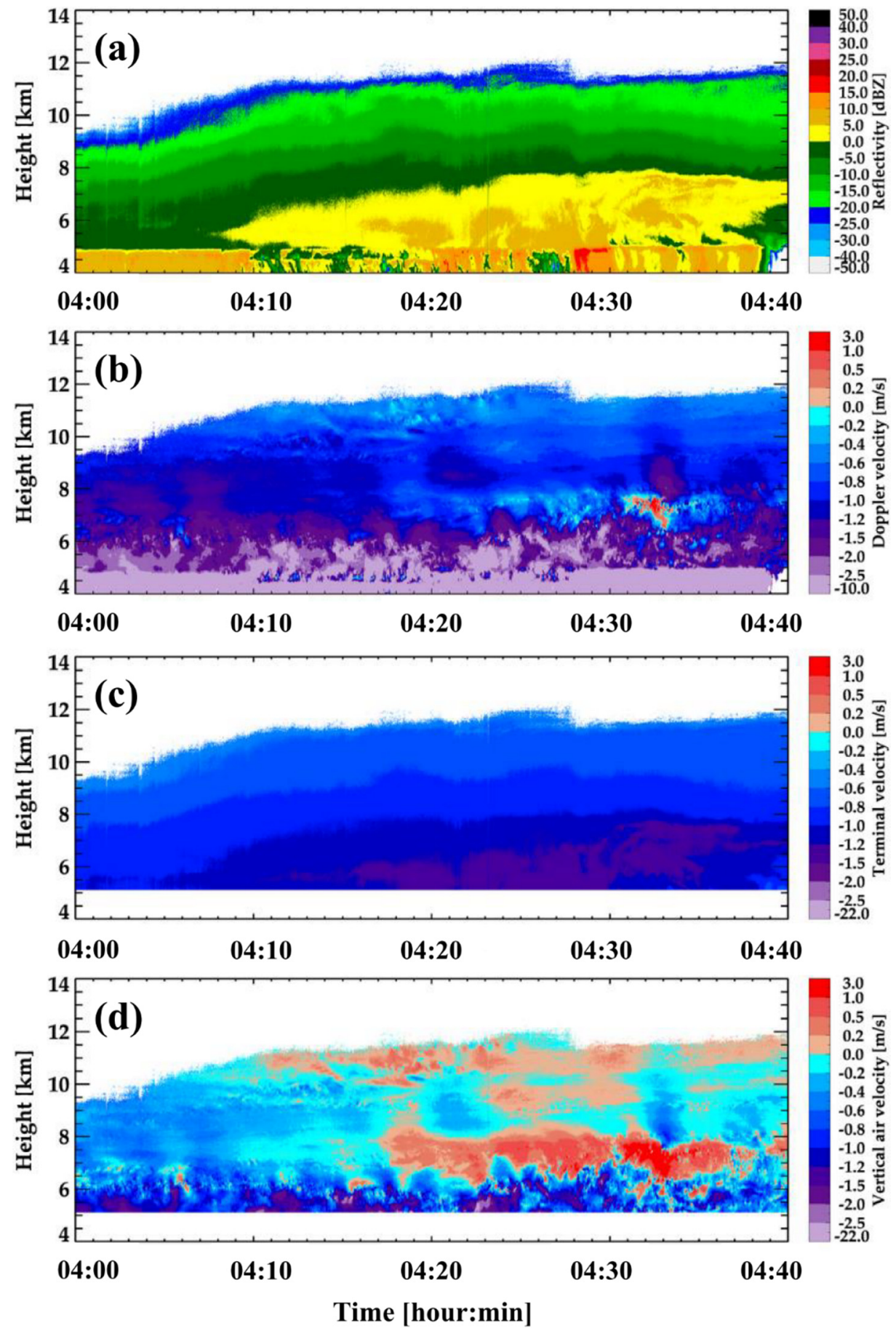

Figure 16. Time-height cross-sections of (a) observed $Z$, (b) observed $V_{D}$, (c) $V_{t}$ retrieved from $V_{t}-Z$ relationship, and (d) retrieved $V_{\text {air }}$ for a case at 04 UTC on 18 June 2013.

The three major layers of upward motion were observed at around 10.5, 9, and $7 \mathrm{~km}$. The upward motion was observed near the cloud echo top with a maximum of $0.5 \mathrm{~m} \mathrm{~s}^{-1}$ at 0418 UTC. After 0418 UTC, a large upward motion occurred in the layer of 6 to $8 \mathrm{~km}$ until 0437 UTC. The alternating feature of downward and upward motions near $6 \mathrm{~km}$ was observed with high-resolution data (2 s data set), indicating $\mathrm{K}-\mathrm{H}$ wave development associated with dynamical instability. A similar periodic motion was shown in the layer between 7.5 and $9.5 \mathrm{~km}$ with a less pronounced and longer period.

These upward motions were clear in CFADs of observed $Z$ and retrieved $V_{\text {air }}$ (Figure 17). As ice particles grew and fell, $Z$ rapidly increases from -20 to $-2 \mathrm{dBZ}$ at $7.5 \mathrm{~km}$. While 
the $V_{\text {air }}$ of about $0.1 \mathrm{~m} \mathrm{~s}^{-1}$ appeared at a height of $11 \mathrm{~km}$, it gradually decreased until reaching a height of $8.5 \mathrm{~km}$. When a significant increase in $Z$ from -2 to $5 \mathrm{dBZ}$ appeared in the layer from 7.5 to $7 \mathrm{~km}$, a dramatic increase in $V_{\text {air }}$ up to about $1 \mathrm{~m} \mathrm{~s}^{-1}$ was observed. This significant increase in $Z$ is related to the rapid growth of hydrometeors due to the strong updraft.

(a) Reflectivity

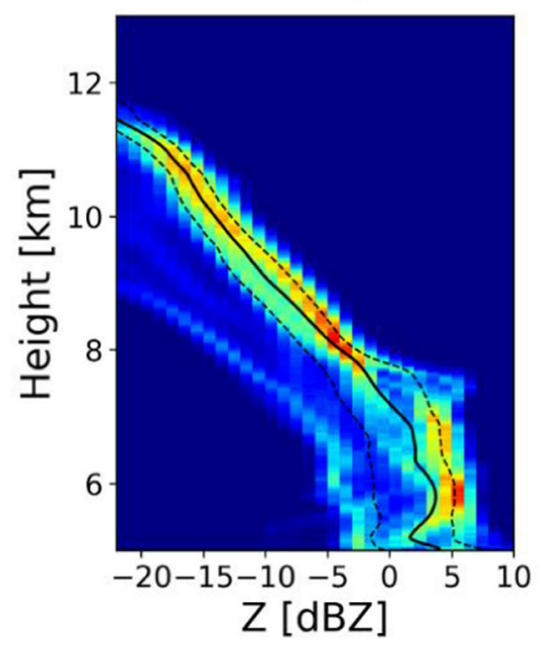

(b) Vertical air velocity

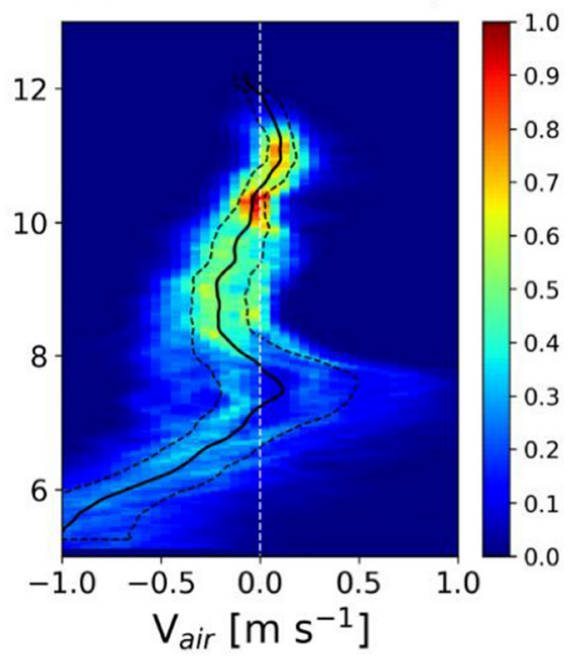

Figure 17. CFADs of (a) observed $Z$ and (b) retrieved $V_{\text {air }}$ of a case at 04 UTC on 18 June 2013. The median and quantiles (25\% and $75 \%$ ) are shown in the solid and dashed lines.

\section{Conclusions}

This study described the long-term characteristics and $V_{\text {air }}$ of ice clouds from vertically pointing measurements from Ka-band cloud radar located at the southern coastal region in South Korea. We interpreted the microphysical and dynamical characteristics of three types (cirrus, anvil, stratiform) of ice clouds for 34 events in terms of observed $Z$, observed $V_{D}$, retrieved $V_{t}, V_{a i r}$, and observed SW. Doppler power spectra were analyzed to identify multi-modal size distributions of snow particles.

Ice clouds with a base height above $6 \mathrm{~km}$ were divided into cirrus, stratiform, and anvil clouds. The $Z$ of the anvil and stratiform clouds was broadly distributed from -30 to $20 \mathrm{dBZ}$, whereas that of the cirrus clouds had a narrower distribution from -30 to $5 \mathrm{dBZ}$. The velocity distribution of the cirrus clouds was narrow with a peak of $-0.6 \mathrm{~m} \mathrm{~s}^{-1}$, which was smaller than that of the anvil and stratiform clouds $\left(-1.2 \mathrm{~m} \mathrm{~s}^{-1}\right)$. In the vertical structures of ice clouds, significant growth of $Z$ and $V_{D}$ appeared in the layer of 8 to $12 \mathrm{~km}$ (roughly a layer of $-40^{\circ} \mathrm{C}$ to $-20^{\circ} \mathrm{C}$ ) for all types of ice clouds. The $V_{D}$ of the stratiform clouds had a unique feature of dramatic reduction near 7 to $8 \mathrm{~km}$ heights (the so-called elongated "S" shape) with an increase in $Z$.

From the average window of $20 \mathrm{~min}, V_{t}$ was calculated, and the $V_{t}-Z$ relationships were then derived for the cloud types. The cirrus clouds had wide distributions of the values of coefficients $a$ and exponents $b$ depending on cloud height. The negative or close-to-zero value of exponent $b$ indicated that an increase in number concentration was dominant over size in the cirrus clouds. The anvil clouds had the largest $b$, indicating that their density increased at a faster rate than that of the stratiform clouds for the same $Z$ increment. The $a$ of stratiform was the largest while the $b$ was in between cirrus and anvil. This indicates a more favorable sedimentation of snow particles in stratiform.

The upward air motions appeared at the top of all ice clouds up to $0.2 \mathrm{~m} \mathrm{~s}^{-1}$, slightly larger in anvil and stratiform clouds. In particular, the upward air motion appeared in the layer of around $7 \mathrm{~km}$ in the stratiform clouds, less distinctive in anvil clouds. This was related to the elongated "S" shape of $V_{D}$ near 7-7.5 km (temperature of approximately $-16--13^{\circ} \mathrm{C}$ ). This unique feature coincided with a bi-modality of Doppler power 
spectrum observed by vertically pointing X-band radar. The bi-modal peaks consisted of pre-existing large ice particles and newly smaller particles that often develop into planar crystals. This layer was associated with actual updraft in dynamical processes and/or broadening of particle size distribution as a result of numerous small pristine ice particles. Thus, we can speculate that the smaller snow particles are likely generated by new ice nucleation and further growth in increased supersaturation. The new nucleation was feasible due to increased supersaturation by upward motion below. In addition, the existence of active dynamical processes was observed with the alternating feature of downward and upward motion for a heavy precipitation case, indicating Kelvin-Helmholtz wave. Further investigation of the unique signature in $V_{D}$ would be useful in improving our understanding of the dynamical and/or microphysical processes of clouds and precipitation.

Author Contributions: This work is the result of significant contributions from all authors. Conceptualization, G.L. and B.-Y.Y.; methodology, B.-Y.Y. and G.L.; software, B.-Y.Y.; validation, B.-Y.Y. and G.L.; formal analysis, B.-Y.Y. and G.L.; investigation, B.-Y.Y. and G.L.; writing-original draft preparation, B.-Y.Y.; writing-review and editing, G.L.; visualization, B.-Y.Y.; supervision, G.L.; funding acquisition, B.-Y.Y. and G.L. All authors have read and agreed to the published version of the manuscript.

Funding: This research was supported by Basic Science Research Program through the National Research Foundation of Korea (NRF) funded by the Ministry of Education (2020R1A6A1A03044834) and by the National Research Foundation of Korea (NRF) grant funded by the Korean government (MSIT) (No. 2021R1A4A1032646).

Institutional Review Board Statement: Not applicable.

Informed Consent Statement: Not applicable.

Data Availability Statement: The data presented in this study are available on request from the corresponding author.

Acknowledgments: This paper is partially based on Bo-Young Ye's thesis. The cloud radar data are provided from National Institute of Meteorological Sciences (NIMS). We also greatly appreciate students and researchers in CARE, KNU, for participating in the summer experiment in 2014-2016.

Conflicts of Interest: The authors declare no conflict of interest.

\section{References}

1. Liou, K.-N. Influence of Cirrus Clouds on Weather and Climate Processes: A Global Perspective. Mon. Weather Rev. 1986, 114, 1167-1199. [CrossRef]

2. Parry, M.L.; Canziani, O.F.; Palutikof, J.P.; van der Linden, P.J.; Hanson, C.E. Climate Change 2007: Impacts, Adaptation and Vulnerability. Contribution of Working Group II to the Fourth Assessment Report of the IPCC; Cambridge University Press: Cambridge, UK, 2007.

3. Jakob, C. Ice clouds in numerical weather prediction models: Progress, problems, and prospects. In Cirrus; Lynch, D.K., Sassen, K., Starr, D.O., Stephens, G., Eds.; Oxford University Press: Oxford, UK, 2002; pp. 327-345, ISBN 0-19-513072-3.

4. Heymsfield, A.J.; Donner, L.J. A Scheme for Parameterizing Ice-Cloud Water Content in General Circulation Models. J. Atmos. Sci. 1990, 47, 1865-1877. [CrossRef]

5. Hong, S.-Y.; Lim, K.-S.S.; Kim, J.-H.; Lim, J.-O.J.; Dudhia, J. Sensitivity Study of Cloud-Resolving Convective Simulations with WRF Using Two Bulk Microphysical Parameterizations: Ice-Phase Microphysics versus Sedimentation Effects. J. Appl. Meteorol. Clim. 2009, 48, 61-76. [CrossRef]

6. Jang, S.; Lim, K.-S.S.; Ko, J.; Kim, K.; Lee, G.; Cho, S.-J.; Ahn, K.-D.; Lee, Y.-H. Revision of WDM7 Microphysics Scheme and Evaluation for Precipitating Convection over the Korean Peninsula. Remote Sens. 2021, 13, 3860. [CrossRef]

7. Morrison, H.; Gettelman, A. A New Two-Moment Bulk Stratiform Cloud Microphysics Scheme in the Community Atmosphere Model, Version 3 (CAM3). Part I: Description and Numerical Tests. J. Clim. 2008, 21, 3642-3659. [CrossRef]

8. Hong, S.Y.; Dudhia, J.; Chen, S.H. A revised approach to ice microphysical processes for the bulk parameterization of clouds and precipitation. Mon. Weather Rev. 2004, 132, 103-120. [CrossRef]

9. Bouniol, D.; Delanoë, J.; Duroure, C.; Protat, A.; Giraud, V.; Penide, G. Microphysical characterisation of West African MCS anvils. Q. J. R. Meteorol. Soc. 2010, 136, 323-344. [CrossRef]

10. Delanoë, J.; Protat, A.; Bouniol, D.; Heymsfield, A.J.; Bansemer, A.; Brown, P. The Characterization of Ice Cloud Properties from Doppler Radar Measurements. J. Appl. Meteorol. Clim. 2007, 46, 1682-1698. [CrossRef] 
11. Heymsfield, A.J.; Wang, Z.; Matrosov, S. Improved Radar Ice Water Content Retrieval Algorithms Using Coincident Microphysical and Radar Measurements. J. Appl. Meteorol. 2005, 44, 1391-1412. [CrossRef]

12. Mace, G.G.; Benson, S.; Vernon, E. Cirrus Clouds and the Large-Scale Atmospheric State: Relationships Revealed by Six Years of Ground-Based Data. J. Clim. 2006, 19, 3257-3278. [CrossRef]

13. Matrosov, S.Y.; Korolev, A.V.; Heymsfield, A.J. Profiling Cloud Ice Mass and Particle Characteristic Size from Doppler Radar Measurements. J. Atmos. Ocean. Technol. 2002, 19, 1003-1018. [CrossRef]

14. Protat, A.; Bouniol, D.; Delanoë, J.; O'Connor, E.; May, P.T.; Plana-Fattori, A.; Hasson, A.; Görsdorf, U.; Heymsfield, A.J. Assessment of Cloudsat Reflectivity Measurements and Ice Cloud Properties Using Ground-Based and Airborne Cloud Radar Observations. J. Atmos. Ocean. Technol. 2009, 26, 1717-1741. [CrossRef]

15. Sassen, K.; Campbell, J.R. A Midlatitude Cirrus Cloud Climatology from the Facility for Atmospheric Remote Sensing. Part I: Macrophysical and Synoptic Properties. J. Atmos. Sci. 2001, 58, 481-496. [CrossRef]

16. Wang, J.; Dong, X.; Xi, B. Investigation of ice cloud microphysical properties of DCSs using aircraft in situ measurements during MC3E over the ARM SGP site. J. Geophys. Res. Atmos. 2015, 120, 3533-3552. [CrossRef]

17. Yan, Y.; Liu, Y.; Liu, X.; Wang, X. Effects of Cloud Microphysics on the Vertical Structures of Cloud Radiative Effects over the Tibetan Plateau and the Arctic. Remote Sens. 2021, 13, 2651. [CrossRef]

18. Ye, B.-Y.; Jung, E.; Shin, S.; Lee, G. Statistical Characteristics of Cloud Occurrence and Vertical Structure Observed by a GroundBased Ka-Band Cloud Radar in South Korea. Remote Sens. 2020, 12, 2242. [CrossRef]

19. Kärcher, B.; Ström, J. The roles of dynamical variability and aerosols in cirrus cloud formation. Atmos. Chem. Phys. Discuss. 2003, 3, 823-838. [CrossRef]

20. Protat, A.; Williams, C. The Accuracy of Radar Estimates of Ice Terminal Fall Speed from Vertically Pointing Doppler Radar Measurements. J. Appl. Meteorol. Clim. 2011, 50, 2120-2138. [CrossRef]

21. Heymsfield, A.J.; Westbrook, C. Advances in the Estimation of Ice Particle Fall Speeds Using Laboratory and Field Measurements. J. Atmos. Sci. 2010, 67, 2469-2482. [CrossRef]

22. Kollias, P.; Tselioudis, G.; Albrecht, B.A. Cloud climatology at the Southern Great Plains and the layer structure, drizzle, and atmospheric modes of continental stratus. J. Geophys. Res. Space Phys. 2007, 112, D09116. [CrossRef]

23. Kollias, P.; Clothiaux, E.E.; Miller, M.A.; Albrecht, B.A.; Stephens, G.L.; Ackerman, T.P. Millimeter-Wavelength Radars: New Frontier in Atmospheric Cloud and Precipitation Research. Bull. Am. Meteorol. Soc. 2007, 88, 1608-1624. [CrossRef]

24. Kalesse, H.; Kollias, P. Climatology of High Cloud Dynamics Using Profiling ARM Doppler Radar Observations. J. Clim. 2013, 26, 6340-6359. [CrossRef]

25. Deng, M.; Mace, G.G. Cirrus Microphysical Properties and Air Motion Statistics Using Cloud Radar Doppler Moments. Part I: Algorithm Description. J. Appl. Meteorol. Clim. 2006, 45, 1690-1709. [CrossRef]

26. Kalesse, H.; Kollias, P.; Szyrmer, W. On using the relationship between Doppler velocity and radar reflectivity to identify microphysical processes in midlatitudinal ice clouds. J. Geophys. Res. Atmos. 2013, 118, 12168-12179. [CrossRef]

27. Orr, B.W.; Kropfli, R.A. A Method for Estimating Particle Fall Velocities from Vertically Pointing Doppler Radar. J. Atmos. Ocean. Technol. 1999, 16, 29-37. [CrossRef]

28. Plana-Fattori, A.; Protat, A.; Delanoë, J. Observing ice clouds with a Doppler cloud radar. Comptes Rendus Phys. 2010, 11, 96-103. [CrossRef]

29. Szyrmer, W.; Tatarevic, A.; Kollias, P. Ice clouds microphysical retrieval using 94-GHz Doppler radar observations: Basic relations within the retrieval framework. J. Geophys. Res. Space Phys. 2012, 117, D14203. [CrossRef]

30. Kim, Y.; Kim, S.-W.; Kim, M.-H.; Yoon, S.-C. Geometric and optical properties of cirrus clouds inferred from three-year groundbased lidar and CALIOP measurements over Seoul, Korea. Atmos. Res. 2014, 139, 27-35. [CrossRef]

31. Heymsfield, A.J.; Iaquinta, J. Cirrus Crystal Terminal Velocities. J. Atmos. Sci. 2000, 57, 916-938. [CrossRef]

32. Matrosov, S.; Heymsfield, A.J. Use of Doppler radar to assess ice cloud particle fall velocity-size relations for remote sensing and climate studies. J. Geophys. Res. Space Phys. 2000, 105, 22427-22436. [CrossRef]

33. Bailey, M.P.; Hallett, J. A Comprehensive Habit Diagram for Atmospheric Ice Crystals: Confirmation from the Laboratory, AIRS II, and Other Field Studies. J. Atmos. Sci. 2009, 66, 2888-2899. [CrossRef]

34. Magono, C. Meteorological Classification of Snow Crystals. J. Jpn. Soc. Snow Ice 1962, 24, 33-37. [CrossRef]

35. Matrosov, S.Y.; Ryzhkov, A.V.; Maahn, M.; de Boer, G. Hydrometeor Shape Variability in Snowfall as Retrieved from Polarimetric Radar Measurements. J. Appl. Meteorol. Clim. 2020, 59, 1503-1517. [CrossRef]

36. Westbrook, C.D.; Illingworth, A.J.; O'Connor, E.J.; Hogan, R.J. Doppler lidar measurements of oriented planar ice crystals falling from supercooled and glaciated layer clouds. Q. J. R. Meteorol. Soc. 2010, 136, 260-276. [CrossRef] 